\title{
Structural performance of RC flat slabs connected to steel columns with shear heads
}

\author{
D.V. Bompa and A.Y. Elghazouli* \\ Department of Civil and Environmental Engineering \\ Imperial College London, UK
}

\begin{abstract}
This paper investigates the structural performance of hybrid members consisting of reinforced concrete flat slabs, with and without shear reinforcement, connected to steel columns by means of fully integrated shear-heads. A detailed account of the results from a series of six large scale tests on this form of hybrid structural system is provided. The test results offer a direct evaluation of the full load-deformation behaviour of the specimens as well as the ultimate punching shear strength attained prior to failure at the critical slab perimeter outside the shear-head region. The experimental findings enable the development of analytical models that depict the rotational response and flexural strength as a function of the shear-head embedment length, layout and section size. Additionally, the test results support the definition of a shear-head dependent control perimeter which is used in conjunction with the analytical slab models for full assessment of punching shear strength. The adequacy of strength predictions incorporated in current design methods for conventional reinforced concrete members are also examined in the paper. It is shown that existing design procedures either lack direct guidance for members provided with shear-heads, or lead to overly conservative strength predictions. Finally, in order to provide a reliable evaluation of the ultimate punching shear strength of hybrid elements, analytical design expressions which account for the characteristics of the shear-head system, are proposed. In comparison with conventional reinforced concrete design provisions, the suggested approach captures in a more realistic manner the influence of the embedded length of the shear-heads for such hybrid members with or without shear reinforcement.
\end{abstract}

Keywords: Reinforced concrete flat slabs; hybrid steel/concrete assemblages; fully-integrated shear-heads; rotational slab response; ultimate slab behaviour; punching shear; stud shear reinforcement.

\section{*Corresponding Author:}

Prof. A. Y. Elghazouli, Department of Civil \& Environmental Engineering, Imperial College London, UK. Email: a.elghazouli@imperial.ac.uk 


\section{Introduction}

Hybrid systems consisting of steel columns with shear heads and reinforced concrete (RC) flat slabs have the potential for combining the structural behaviour synergies and practical construction merits of the constituent elements. Early interest in shear head configurations was shown with the development of high rise structures in the United States when the first systems to transfer loads between concrete columns and flat slabs were patented [1,2]. The use of shear-head systems against punching shear in conventional RC flat slabs was subsequently reported in various studies. Corley and Hawkins proposed a design procedure (implemented by the American Concrete Institute, ACI) as a result of a series of tests on cruciform shear-head systems fully embedded in the slab and consisting of two perpendicular I-sections placed between longitudinal reinforcement mats [3]. It was noted that shear-heads can increase the punching shear strength of RC flat slabs by up to $75 \%$. Other intricate shear-head systems were reported in recent decades for RC flat slabs, including composite cruciform systems consisting of vertical plates acting as shear-heads and provided with welded studs [4], fan-shaped systems made of wide tee pieces [5], and the Geilinger mushroomhead made of vertical plates bolted to the flanges of the column and surrounded by U-shaped edge beams [6]. Chana and Birjandi also carried out an extensive testing programme on typical cruciform systems having various arrangements of steel beams, including a closed-type system provided with edge beams [7].

The connection between steel columns and flat slabs is typically made by a steel insert that is welded to the column and integrated into the flat slab. Recent investigations on flat slab to tubular columns employed cruciform shear-head systems [8,9]. The assemblages consisted of four I-shaped steel profiles with various lengths welded to the four faces of the rectangular columns. They showed improved punching shear strengths in comparison with conventional RC flat slabs [10]. Tests were also reported on shear-head systems that improve the ductility of the connection under cyclic loading in which, the behaviour of the slab was controlled by the strength and stiffness of the shearhead [11]. The experimental and numerical results indicated that the high ductility of the steel column to concrete flat slab connection can be obtained in the case of partially-integrated shearheads if the dissipative elements are designed to yield in shear. Other systems adopted vertical connection plates welded to a steel column that is connected to a partially-embedded H-shaped shear-head within small scale slab specimens with or without transverse studs [12]. The results of the investigation proposed a method that accounts for the cumulative contribution of the concrete, connection plate as well as the effect of the studs on the ultimate punching shear strength.

In contrast with the limited studies carried out on flat slab-to-steel column assemblages, the behaviour of flat slab-to-RC column has been investigated in detail, for members with and without shear reinforcement. Early experimental programmes studied the influence of the concrete strength, top and bottom reinforcement ratio, size of the column, amount and position of the shear reinforcement [13]. Tests carried out on circular slabs with ring and two-way reinforcement supported on circular columns led to the development of early analytical assessment and design method for flat slabs without shear reinforcement [14]. A test programme on a series of forty three members investigated the basic mechanisms of failure in shear for RC flat slabs and footings [15]. It provided results that influenced the current ACI design procedure for conventional RC members [16]. More recent studies involving large scale slab specimens enabled a better understanding of the influence of size effect on element behaviour [17]. 
Other experimental programmes provided a basis for mechanical models to estimate the punching resistance and as well as the flexural capacity of axisymmetric RC slabs subjected to concentrated loads or reactions [18]. Experimental results from members made of high strength concrete were analysed numerically and further adopted in a concrete brittleness dependent failure criterion required for ultimate strength assessment [19]. The detailed investigations reported by Guandalini et al and Muttoni [20,21] led to an analytical model to predict the punching shear strength as a function of the slab rotation, which in a simplified manner forms the theoretical basis behind the fib Model Code (MC) 2010 [22]. Various transverse reinforcement types, layouts and configurations were reported. Previous studies also examined the influence of slab thickness in the presence of orthogonally placed transverse studs [23], and the effect of anchorage on the effectiveness of the shear reinforcement in the punching zone [24]. Moreover, a theoretical model, based on axisymmetric models [14,18], to analyse the punching shear resistance of RC flat slabs with shear reinforcement for concentric loading, was proposed and validated on 12 full scale specimens by Gomes and Regan [25]. A slab rotational dependent contribution of shear reinforcement to punching shear strength was also proposed by Fernandez and Muttoni [26]. A test series of 16 flat slabs with practical thicknesses ranges and with various transverse reinforcement arrangements [27] was used to verify the effectiveness of the American and European design methods [16,28] as well as of the mechanical models $[21,26]$.

For hybrid steel column-flat slab systems, there is a dearth of research studies involving full scale tests on members with fully integrated shear-heads without transverse reinforcement and, importantly, investigations on systems incorporating transverse reinforcement are lacking. Existing assessment methods are typically based on empirical assumptions that are not based on the actual behavioural characteristics of such hybrid members. Available studies and design approaches do not provide adequately validated information regarding the shear force distribution and slab critical regions in shear-head reinforced members. Additionally, there is a need for a detailed insight and understanding of the contribution of conventional transverse reinforcement to the strength of hybrid members with fully integrated shear-heads. Existing design procedures for shear-heads systems are limited, with some guidance on the design of flat slabs with shear-heads included within the procedures for conventional RC members in ACI318 and MC2010 [16, 22] whilst Eurocode 2 (EC2) [28] does not offer any guidance for the design of members provided with shear-heads.

The investigation carried out in the paper deals with the ultimate behaviour of cruciform H-shaped shear-head systems fully embedded into the RC flat slab and welded to the steel column. A full account of the results of six large scale tests is given, in which the embedded length and crosssection of the shear-head as well as the slab thickness are maintained, whereas the configuration of the shear-head assemblage, flexural reinforcement ratio and the contribution of transverse reinforcement are varied. Based on the test results, a detailed axisymmetric analytical model to assess the rotational response of hybrid slabs reinforced with shear-heads is proposed. Simplified expressions to represent the rotational response in an idealised bi-linear form, as well as the flexural strength of hybrid members, are also provided. Moreover, recent approaches for determining the punching shear strength of RC flat slabs [21,22,26] are employed, in conjunction with shear-head dependent factors as well as with the predictions of the hybrid rotational models proposed in this paper, for strength assessments of the hybrid forms considered herein. To this end, 
simplified yet realistic analytical design expressions for predicting the punching shear strength of hybrid flat slab systems with and without shear reinforcement are proposed.

Based on the approaches proposed in this paper, for hybrid members without shear reinforcement, the punching shear strength is assessed on three levels of refinement (by considering the definition of shear-head dependent critical perimeter and associated assumptions) as follows:

- Detailed assessment approach: where the rotational response is predicted by the axisymmetric hybrid model, whereas the punching shear strength is obtained from the intersection between the load-rotation $(V-\psi)$ curve and an established concrete failure criterion [21].

- Simplified assessment approach: incorporating an idealised bi-linear hybrid model for the prediction of the $V-\psi$ curve that is further intersected with the same failure criterion [21].

- Analytical design expressions: in which the punching shear strength is a function of the rotation at failure (determined by the bi-linear $V-\psi$ model) and a conservative failure criterion represented by a punching shear parameter $\left(k_{\psi}\right)$ [22].

Additionally, for hybrid slabs with shear reinforcement, the strength enhancement provided by transverse bars is considered to be dependent on the shear-head geometry, and supplements the concrete contribution which is a function of the punching shear strength of members without shear reinforcement. In the case, the three approaches listed above are modified as follows:

- In the detailed assessment approach, the contribution of the shear reinforcement is determined using an existing analytical model [26] in which the shear force carried by the transverse bars is dependent on the hybrid slab rotation evaluated through the axisymmetric hybrid model.

- The simplified assessment approach follows the same procedure as above [26], but utilises the idealised bi-linear rotational model rather than the axisymmetric hybrid model.

- The analytical design expressions are modified to account for the shear reinforcement contribution as a function of the hybrid slab rotation at failure [22] (assessed using the idealised bi-linear rotational model).

Finally, comparative assessments, using the experimental and analytical findings from this investigation as well as other relevant test results available in the literature [8-11], are carried out against existing codified provisions. The main implications on the practical design of hybrid flat slab-to-steel column systems, of the type considered in this study are highlighted within the discussions.

\section{Experimental Programme}

\subsection{Testing arrangement and instrumentation}

Figure 1a provides a schematic representation of the test setup, whereas Figure $1 \mathrm{~b}$ shows a view of the general layout-out of the testing arrangement. The test rig was designed to enable realistic experimental assessment of hybrid steel column-to-RC flat slab assemblages up to failure. The load was introduced directly to the column through an actuator of $3500 \mathrm{kN}$ capacity, and was recorded 
by means of a load cell placed between the actuator and an intermediate hinge. Eight support plates of $40 \mathrm{~mm}$ thickness and $180 \mathrm{~mm}$ diameter were tied through $32 \mathrm{~mm}$ reaction bolts to the strong floor, with their longitudinal axis at $964 \mathrm{~mm}$ radius from the column centre. Reaction forces at supports were instrumented by means of $600 \mathrm{kN}$ load cells. All tests were carried out in force control mode. The load was applied in $20 \mathrm{kN}$ increments and maintained constant for a period of 30 seconds after each load step was completed. Visual tracking of the crack initiation and propagation was coupled by a digital image correlation system to record the initiation of flexural and shear cracking on the top face of the slab.

Throughout the testing process, the behaviour of each hybrid specimen was monitored by means of three data acquisition systems. A series of thirteen displacement transducers were employed to record the deflected shape of the specimen, both at the top (N-S axis) and bottom (N-S and E-W axes), as well as a central transducer to record the vertical displacement at the centre of the column (Figure 1a,b). Three inclinometers were used to measure the slab rotations for the two orthogonal and the diagonal directions. The strains on the reinforcement bars (longitudinal and transverse, if present) and the shear-head (top flanges and web) were recorded by means of electrical strain gauges of $5 \mathrm{~mm}$ length. The surface concrete strains were recorded using twelve transducers on the bottom face of the specimen. Fourteen transducers acting as surface gauges were used to monitor the tensile strain and cracking on the top face of the specimen. The surface gauges were distributed evenly between the orthogonal slab directions and the diagonals of the slab. The sectors of the member that include the shear-heads are referred to as 'hybrid slab sectors' (i.e. orthogonal to column sides). Each hybrid sector is divided into a composite segment containing the shear-heads and a non-composite segment delimited by the tip of the shear-head and the slab edge. The sectors without shear-heads (diagonals of the member) are referred to as 'reinforced concrete (RC) sectors'.

\subsection{Specimen and material details}

The test programme consisted of a series of six large scale hybrid members. The dimensions of the specimens were designed with due account for practical considerations and experimental constraints, with the aim of obtaining failure primarily governed by punching shear in most cases. Figure 2 depicts a typical arrangement of tested assemblages, whilst Table 1 summarises the main specimen details. The nominal thickness of the flat slab was $h=225 \mathrm{~mm}$, whereas the in-plane dimensions were $2.2 \mathrm{~m} \times 2.2 \mathrm{~m}$. The tested members replicated the connection region between a steel column and a heavily loaded continuous flat slab with moment span of about $4.5 \mathrm{~m}$. The isolated members were made of a closed section steel column stub that had four shear-heads welded directly to it and fully embedded in the RC flat slab part. The slab reaction radius $r_{q}=964 \mathrm{~mm}$ depicts the zero bending moment line, as determined by the supports and dictated by the location of the floor bolts within the strong floor of the laboratory (Figure 2a,b).

The parameters examined directly in the tests included the flexural reinforcement ratio $\left(\rho_{l}\right)$, the presence of transverse reinforcement $\left(\rho_{w}\right)$ and the presence of the continuity plate around the column. The slab thickness $(h)$, in-plane configuration and embedded length of the shear-head $\left(l_{v}\right)$ were maintained constant. The embedded length and section size of the shear-head were designed to avoid plastic deformations in the steel insert. The effective depth of the slab was dictated by the presence of the continuity plate and bar diameter, and varied from 172 to $178 \mathrm{~mm}$ (Table 1). On average, the top concrete cover was $35 \mathrm{~mm}$ and the bottom concrete cover was $12.7 \mathrm{~mm}$. 
The conventional concrete flexural reinforcement ratio $\left(\rho_{l}\right)$ varied between $0.33 \%$ and $1.37 \%$. The top mesh of the four HS13 slab specimens was made of $16 \mathrm{~mm}$ bars spaced at $83 \mathrm{~mm}$, whereas the bottom mesh of $10 \mathrm{~mm}$ bars at $83 \mathrm{~mm}$ spacing (Figure 2a,b,c). The top reinforcement mesh of Specimen HS07-C0 consisted of alternating $10 \mathrm{~mm}$ and $16 \mathrm{~mm}$ bars, spaced at $200 \mathrm{~mm}$ intervals. Specimen HS03-00 had the lowest amount of flexural reinforcement, consisting of $10 \mathrm{~mm}$ bars at $135 \mathrm{~mm}$ spacing at their centres. The bottom mesh of HS03-00 and HS07-C0 was identical to the top mesh of HS03-00. All the reinforcement bars placed on the tension side of the specimens were provided with hooks to ensure bond requirements, and two of bars crossed the column on the top side for both orthogonal directions to ensure continuity.

Specimens HS13-0T and HS13-CT were provided with transverse reinforcement placed around the shear-heads. The in-plane arrangement of the transverse reinforcement was chosen in order to avoid any potential failure outside the shear reinforced region. A total number of 108 and 112 studs were placed in HS13-0T and HS13-CT, respectively (Figure 2b,d). The first studs were placed at $s_{w, 0}=$ $70 \mathrm{~mm}$ from the column corners and edges of the shear-head flanges. The studs were welded to the rail to ensure stud alignment within the slab and had hot forged heads three times the diameter of the bar. The transverse reinforcement consisted of $h_{b w}=190 \mathrm{~mm}$ long, $d_{b w}=10 \mathrm{~mm}$ double-headed, stud rails at stud spacing of $s_{w 1}=150 \mathrm{~mm}$ (Figure 2d). The studs enclosed the two longitudinal reinforcement mats, and were orthogonally arranged within the reaction radius $\left(r_{q}\right)$ as depicted in Figure 2b.

The adopted column size was HEB240 in all specimens, with two $20 \mathrm{~mm}$ plates welded on the free edges of the profile, resulting in a closed box section $\left(b_{c, E W} \times b_{c, N S}=240 \mathrm{~mm} \times 280 \mathrm{~mm}\right)$. Thirty millimetres load transfer plates were welded to the top and the bottom part of the column. Full penetration of the longitudinal reinforcement through the column was allowed by $25 \mathrm{~mm}$ drilled gaps. European section HEB 100 type shear-heads, with embedded length of $l_{v}=370 \mathrm{~mm}$, were welded symmetrically to the four faces of the column. They were fully embedded in the RC flatslab. Ten millimetres continuity plates around the column were placed in the case of Specimens HS13-C0, HS07-C0 and HS13-CT (Figure 2e). Section details of the HEB steel profiles are given in Table 2.

Ready mix concrete of nominal Grade C25/30, with a maximum aggregate size of $d_{g}=10 \mathrm{~mm}$, was used in the tested specimens. Samples to assess the compressive and tensile strength at 28 days and on the day of testing were obtained from each concrete batch. The samples used to determine the strength at 28 days were submersed in water, whereas others were kept in the same conditions as the slabs. The average compression strength obtained by means of cylinder tests on at least four samples varied from 27.4 to $35.6 \mathrm{MPa}$ at 28 days, and 27.9 to $39.2 \mathrm{MPa}$ on the day of testing. The cube strength varied from 30.9 to 42.3 at 28 days, whereas on the day of testing it varied between 31.3 $\mathrm{MPa}$ to $43.8 \mathrm{MPa}$. The tensile strength by means of splitting tests varied from 2.15 to 2.69 $\mathrm{MPa}$ on the day of testing, and between $2.24 \mathrm{MPa}$ and $3.03 \mathrm{MPa}$ at 28 days. The average strength values are given in Table 1 for each specimen.

Steel coupon tests were carried out in order to assess the characteristics of the materials used in the shear-heads and reinforcement bars. The yield strength of the HEB100 shear-head flanges was $f_{y, 0.2 \%}=457 \mathrm{MPa}$ and the yield strength of HEB100 shear-head webs was $f_{y, 0.2 \%}=461 \mathrm{MPa}$. The 16 $\mathrm{mm}$ reinforcement bars used as tension reinforcement in Specimen HS13 had a yield strength of 
$f_{y, 0.2 \%}=536 \mathrm{MPa}$, whereas the $10 \mathrm{~mm}$ compression bars had $f_{y, 0.2 \%}=544 \mathrm{MPa}$. The longitudinal bars in Specimens HS03-00 and HS07-C0 had $f_{y, 0.2 \%}=577 \mathrm{MPa}$ for the $16 \mathrm{~mm}$ bars and $f_{y, 0.2 \%}=547$ $\mathrm{MPa}$ for the $10 \mathrm{~mm}$ bars. The yield strength of the $10 \mathrm{~mm}$ transverse studs was $f_{y, 0.2 \%}=566 \mathrm{MPa}$. The average values of steel properties, determined on a minimum of three samples, are provided in Table 2.

\section{Test Results and Observations}

\subsection{Specimens without conventional shear reinforcement}

The applied load $\left(V_{i}\right)$ versus the column deflection $(\delta)$ curves for the six specimens are plotted in Figure 3. Specimens HS13-00 and HS13-C0, without shear reinforcement and with high amounts of longitudinal reinforcement $\left(\rho_{l} \sim 1.37 \%\right)$ exhibited similar behaviour throughout the entire loading process reaching an ultimate strength of $V_{\text {test }}=1005 \mathrm{kN}$ and $V_{\text {test }}=991 \mathrm{kN}$, respectively. Specimens with intermediate (HS07-C0) and low (HS03-00) flexural reinforcement ratios had lower ultimate strengths. The specimen with the lowest conventional flexural reinforcement ratio $(\rho l)$ failed at $V_{\text {test }}$ $=582 \mathrm{kN}$, whereas Specimen HS07-C0 failed at $V_{\text {test }}=880 \mathrm{kN}$. Similar behaviour was observed for all hybrid elements at early loading stages characterized by flexural cracking. Crack widths and pattern depended on the amount of bending reinforcement. The general in-plane crack path was characterized by orthogonal and diagonal lines, similar to typical yield-line patterns. Wider cracks were observed in the region of the shear-head flanges for the weak axis rotation. This led to a slight non-symmetric rotational behaviour, primarily, due to the uneven dimensions of the column (i.e. on average, $52 \%$ of the load was transferred to the EW reaction ties, whereas $48 \%$ was transferred to the NS reaction ties). Due to practical fabrication reasons, the shear-head assemblages in the NS direction were not provided with stiffener plates between the two $20 \mathrm{~mm}$ thick plates welded to the column; this introduces some relative out-of-plane flexibility compared to the orthogonal EW direction and contributes to a slight asymmetry in the rotational response of the member.

According to the surface gauge measurements, for HS13-00, flexural cracking firstly developed in the hybrid sector, whereas signs of shear cracking were recorded at loads around $80 \%$ of the ultimate strength. To gain detailed insight into the behaviour of the hybrid members, further processing of the surface gauge measurements was carried out by considering simplified linear strain compatibility between the tension and compresion faces of the slab. This enabled the calculation of an approximate position of the neutral axis for low levels of shear deformation (prior to the development of the critical crack). For HS13-00, at shear cracking, the neutral axis in the hybrid sector at the tip of the shear-head, as a result of radial moment action, was about $39 \mathrm{~mm}(\mathrm{c} / \mathrm{d}$ $=0.22$ ). Similarly, the neutral axis was at $c / d=0.15$ at shear cracking for the NS tangential moment action. In the RC sector, the ratio $c / d$ was maintained rather constant from througout the entire loading process ( $\operatorname{radial} c / d=0.35$, tangential $c / d=0.26$ ). In the radial moment action, the neutral axis prior to shear cracking was $c / d=0.36$ whereas in the tangential moment action it reached $c / d=0.3$ showing a redistribution of internal forces. Failure occurred at an applied load of $V_{\text {test }}=1005 \mathrm{kN}$ and a corresponding column vertical displacement of $\delta_{V \text { test }}=8.80 \mathrm{~mm}$. The crack pattern at ultimate is illustrated in Figure 4a.

The behaviour of Specimen HS03-00, provided with the lowest amount of flexural reinforcement, 
was characterized by large bending deformations with flexural strains above yield. According to strain gauge measurements, both the flanges and web of the shear-head remained in the elastic regime up to ultimate (Figure $4 \mathrm{~b}$ ). The first surface cracks were recorded as a result of tangential moment action at $42 \mathrm{kN}$ in the $\mathrm{RC}$ sector and $66 \mathrm{kN}$ in the hybrid part. Radial moment action produced, before shear cracking, a drop in the neutral axis to $c / d=0.14$ and $c / d=0.20$ in the hybrid and $\mathrm{RC}$ sectors, respectively. For the tangential action, the ratio between the compressive zone and effective depth of the slab were $c / d=0.20$ and $c / d=0.29$ in the hybrid and RC sectors, respectively. The recorded ultimate strength was $V_{\text {test }}=582 \mathrm{kN}$ at a corresponding displacement of $\delta_{V t e s t}=13.0$ $\mathrm{mm}$.

Despite the presence of the continuity plate around the column, Specimen HS13-C0 attained an almost identical ultimate strength to HS13-00 characterized by a slightly enhanced stiffness due to the increase in shear-head cross-section in the maximum moment region (i.e. the continuity plates increasing the effective flange thickness and width). Tangential flexural cracking was firstly recorded at $34 \mathrm{kN}$ in the monitored $\mathrm{RC}$ sector and at $64 \mathrm{kN}$ in the hybrid part, whereas radial cracking was firstly recorded at $72 \mathrm{kN}$ (Figure 4c). Both the hybrid and RC sectors showed a more uniform in-plane strain distribution. The neutral axis prior to shear cracking was at $c / d=0.35$ in the region corresponding to the radial moment action and $c / d=0.40$ in the region corresponding to the tangential moment action. Failure occurred at an applied load of $V_{\text {test }}=991 \mathrm{kN}$ and a corresponding column displacement $\delta_{\text {Vtest }}=7.00 \mathrm{~mm}$.

Specimen HS07-C0 with average flexural reinforcement and continuity plate developed intermediate rotational response in comparison with HS13-C0 and HS03-00. Even though the reinforcement ratio was lower, the presence of the continuity plate enhanced the member stiffness to a level similar to that recorded for HS13-00. Tangential flexural cracking was initiated at $52 \mathrm{kN}$ in the RC sector and at $80 \mathrm{kN}$ in the hybrid part. Radial flexural cracking occurred later at $136 \mathrm{kN}$ (Figure 4d). The measurements indicate that punching shear cracks formed at about $70 \%$ of the ultimate strength of $V_{\text {test }}=880 \mathrm{kN}$ (corresponding to a column vertical displacement at failure $\delta_{\text {Vtest }}$ $=8.15 \mathrm{~mm}$ ). The radial moment action before shear cracking produced a drop in neutral axis at $c / d$ ratios of 0.23 and 0.25 for the hybrid and $\mathrm{RC}$ sectors, respectively. On the other hand, in the tangential direction the neutral axis was located at $c / d=0.24$ in the hybrid sector and $c / d=0.28$ in the RC part. Punching shear governed at ultimate showing a failure mode characterized by the dislocation of a body made of the shear-head assembly and surrounding concrete from the member. The opening of the governing punching shear crack at failure was $0.59 \mathrm{~mm}$, as recorded by a displacement transducer positioned to monitor changes in slab thickness.

No plastic levels were recorded by the electrical strain gauges located on the longitudinal reinforcement as well as the flanges and webs of the shear-heads of Specimens HS13-00 and HS13$\mathrm{C} 0$. The recorded strains on shear-head flanges were about one third of the yield strain. It was observed that failure occurred due to the development of a punching shear crack that initiated in the hybrid sector at the concrete-to-composite interface (about $1.0 d$ from the tip of the shear-head) due to the force transfer through struts supported on the bottom flange of the shear-head. Furthermore, the failure propagated towards the RC sector producing an asymmetric tri-dimensional surface bounded by an octogonal pattern on the top face and a rectangular pattern on the bottom face of the slab. 
Figure 5 illustrates the cross-sectional crack patterns of specimens without transverse reinforcement. The slab cut was made at $200 \mathrm{~mm}$ from the column face for the N-S axis of the slab. Considering that the punching shear crack inclination angle is given by a straight line that connects the compression zone to the longitudinal reinforcement, their values were between $16^{\circ}$ to $30^{\circ}$. This illustrates rather flat inclinations than the typical case of RC flat slabs. This seems to be influenced by the rather short distance between the strut base and reaction support as well as the concrete cover. The reduction in flexural reinforcement produced stronger dislocation of the punching cone and a higher activation of dowel action, but little influence was observed in the shape of the failure surface (Figure 5b). The failure of Specimens HS13-00, HS13-C0 and HS07-C0 was attributed to punching shear. On the other hand, Specimen HS03-00 exhibited a ductile behaviour of the flexural reinforcement yet failure eventually occurred due to the dislocation of a punching cone, and was thus characterised as a failure mode similar to 'flexural punching' in conventional RC flat slabs.

\subsection{Specimens with tranverse shear reinforcement}

Specimens HS13-0T and HS13-CT, provided with shear reinforcement as double headed studs welded on rail, exhibited improved ultimate capacity and ductility. Due to the presence of effective transverse shear reinforcement, the ultimate capacity of the two specimens was about double the corresponding specimens without shear reinforcement (i.e. HS13-00 and HS13-C0). More pronounced asymmetric behaviour was captured by the reaction load cells when compared to their transversely unreinforced counterparts. Although the ultimate strengths of HS13-0T and HS13-CT differed by $12.5 \%$, their corresponding ultimate vertical displacement of the columns were similar $\left(\delta_{\text {test }}=21.7 \mathrm{~mm}\right.$ and $\left.\delta_{V \text { test }}=21.6 \mathrm{~mm}\right)$. Similar crack patterns were also recorded for both specimens in the hybrid and RC sectors based on tangential moment action (crack initiation was recorded at $75 \mathrm{kN}$ ) (Figure 6). Cross-sectional cuts through the specimens showed punching shear cracks forming between the shear-heads and supports (Figure 7).

For HS13-0T, surface gauge measurements indicated that at ultimate the neutral axis was $c / d=0.05$ for the radial moment action, both in the hybrid and $\mathrm{RC}$ sectors. The tangential moment action produced more intense cracking on the RC than on the hybrid sector. At ultimate, the neutral axisto-effective depth ratios were $c / d=0.14$ and $c / d=0.26$, respectively. The longitudinal reinforcement micro-strains recorded at the column face reached yield levels at $1300 \mathrm{kN}$. Crosssectional cuts through the specimen indicated a distributed punching shear failure with multiple inclined cracks forming between the shear-head and supports (Figure 7a). Several studs were intersected by the punching shear crack, and fractured at ultimate. Figure $7 \mathrm{~b}$ illustrates a fractured stud below its head. The strains on the shear-head components were below the yield limit. Shear cracking was initiated around $800 \mathrm{kN}$, corresponding to signs of activation of the transverse studs as recorded by the strain gauges.

Although the behaviour of HS13-CT was similar to HS13-0T over the loading process, Specimen HS13-CT exhibited the highest capacity of all the tested members. Extensive yielding of the longitudinal bars, initiated at about $1100 \mathrm{kN}$, was combined with elastic behaviour of the shear-head assembly. The enhanced effect of the continuity plate kept the stresses within the elastic range. The critical moment region was shifted away from column face and stabilised the behaviour at ultimate. 
Flexural cracking initiated at about $44 \mathrm{kN}$ in the hybrid sector for tangential moment action and was superseded by flexural radial cracking and by opening of the punching shear crack (at load levels around $900 \mathrm{kN}$ ). The cross-sectional cut of the specimens showed a nearly symmetric critical punching shear crack that originated from the region of the bottom flange of the shear-head. The inclined crack interface intersected a higher amount of studs (Figure 7c), when compared with HS13-0T, resulting in the activation of a larger number of transverse bars and higher contribution to the ultimate strength (Figure 7d). The recorded cross-sectional punching shear cracks, combined with yield behaviour in the transverse and longitudinal bars, indicated a punching failure mode governed by flexural yielding linked to studs fracture and elastic response of the shear-head.

The exact contribution of the transverse reinforcement to the punching shear strength of hybrid flat slabs depends on the stud layout, diameter and spacing; shear-head system layout and geometry; slab geometry and boundary conditions, among other factors. In order to investigate this, the strain gauge measurements are used as basis to determine the amount of transverse bars activated at ultimate. The effective layout of the transverse reinforcement in Specimens HS13-0T and HS13-CT as recorded before casting is represented by dots in Figure 8 . The location of each electrical strain gauge is labelled with an ' $\mathrm{SW}$ ' term and number. The corresponding strain levels in the transverse reinforcement are also illustrated in the diagrams at the bottom right corners in Figure 8.

The load-strain diagrams indicate a sequential activation of the transverse bars. In case of Specimen HS13-0T, the first activated stud was SW3 at $96 \%$ of $V_{\text {test }}$ followed by SW1 at $98 \%$ of the ultimate strength and SW2 at $99 \%$ of $V_{\text {test. }}$. No other strain gauges recorded strain levels above the yield limit. Accordingly, and in conjunction with the saw-cuts shown in Figure 7 and the top crack pattern depicted in Figure 6, it was concluded that at least twenty four studs were intersected by the punching shear crack (marked with solid black dots in Figure 8a). On the other hand, for Specimen HS13-CT, five of the eight strain gauges recorded strains above the yield level. The first stud activated was SW2 at $88.5 \%$ of $V_{\text {test }}$, followed by SW1 at $92.9 \%$, SW4 at $97.8 \%$, SW3 at $99.6 \%$ and SW7 at $99.9 \%$ of the ultimate recorded strength. It was observed that, besides the studs adjacent to the shear-head flanges, those located at the composite-to-concrete interface were activated, indicating that a minimum of twenty eight studs contributed to the ultimate strength of the specimen (marked with solid dots in Figure 8b). These amounts of transverse bars are used as a basis for the assessment of the punching shear strength of Specimens HS13-0T and HS13-CT in subsequent sections of this paper.

\section{Load-Rotation Response}

\subsection{Behavioural considerations}

Axisymmetric yield line mechanisms can be employed in effective analytical models to obtain the rotational response and flexural strength of conventional RC slabs [14, 18, 21]. These require a set of equilibrium equations between the energy introduced in the system by the load application and the energy dissipated due to the rotation of the rigid sectors along the yield lines. In the case of steel column-to-flat slab assemblages, an axisymmetric behaviour can be accounted for by assuming that the relatively stiff shear-heads in conjunction with the continuity reinforcement transfer the entire load from the steel assemblage to the RC member. The in-plane layout of the bending mechanism 
of such a member may be divided into hybrid sectors and conventional RC sectors (Figure 9a), identified as hybrid slab sectors and RC slab sectors in Section 3, respectively. In each sector type, corresponding constitutive, compatibility and equilibrium relationships apply. For isolated members, each sector is considered to be bounded by tangential cracks and radial lines representing the borders of distinct regions. The radial sectors rotate around the centre located at the level of the neutral axis (Figure 9b). In the case of steel column-to-flat-slab members, the shear-heads and longitudinal reinforcement ensure continuity between the two components.

For the radial moment action, two discontinuities exist within the radius of the member, both for the hybrid and RC type sectors: the first is located at the column face, where no monolithic connection between the steel column and RC flat slab exists; the second is located at the tip of the shear-head where the composite section changes to RC. Each sector is divided into two rigid segments that rotate independently around the centre of rotation, employing wedge elements located between the column face $r_{c}$ and the inclined crack surface $r_{v}$, and outer slab segments delimited by the inclined surface $r_{v}$ and the slab boundary $r_{s}$ (Figure 9c,d). For the hybrid sectors, the wedge element, also referred to as the 'inner hybrid slab segment', is characterised by composite behaviour, whereas the outer slab segment behaves as a conventional RC element (non-composite). The use of wedge elements enables effective determination of the dowel force at the inclined cracked interface [18] as well as the internal transfer of forces between the shear-head (as depicted in Figure 9e) and the flexural reinforcement.

Previous investigations on RC flat slabs showed that the radial moment is concentrated in the vicinity of the column and decreases abruptly with the radius of the slab [14]. Tests reported in Sections 2 and 3 provide evidence that the radial strains and radial moment exhibit high peaks near the column interface, both for the hybrid and RC sectors (Figure 10). In the case of the regions in which shear-heads are present, concentration of strains occurs at the shear-head tip (composite-toconcrete interface). For members without transverse reinforcement, the shear-head behaved as a rigid insert up to ultimate, and the hybrid sectors developed distinct behaviour over the wedge (inner hybrid slab segment - composite) and outer slab segment (non-composite). The development of smaller compression strains combined with larger crack-widths in the hybrid sector, compared to larger compression strains combined with wider flexural cracks in the $\mathrm{RC}$ sector, suggests that a higher tangential moment is acting on the shear-head regions as illustrated by the values of $c / d$ ratios in Section 3.

\subsection{Analytical representation}

The rotational response is assessed by considering separate compatibility and equilibrium equations in the 'reinforced concrete' and 'hybrid' sectors. The two sectorial regions showed similar rotations during the tests. The bottom right-hand diagram in Figure 11 depicts the experimental load-rotation response of HS03-00. For this specimen (with a low conventional reinforcement ratio $\rho_{l}=0.33 \%$ ), the radial bending moment, for orthogonal directions, produced slightly lower average rotations (hybrid sectors, recorded by inclinometers $\mathrm{N}$ and $\mathrm{W}$ ) than the radial bending moment for the diagonal direction ( $\mathrm{RC}$ sector, recorded by inclinometer $\mathrm{NW}$ ). This was primarily influenced by the position of the supports. Similar behaviour was recorded for the other specimens reported in Section 3. In the analytical model developed in this section, the small difference in rotation between the two 
sectorial types is neglected; i.e. $\psi_{i, k}=\psi_{i, c}$. Between the face of column $\left(r_{c}\right)$ and composite-toconcrete interface $\left(r_{v}\right)$ a linear variation of forces is assumed. Inside the wedge, the radial and tangential behaviour are equal $\left(\psi_{r}=\psi_{t}\right)$. Outside the wedge, the behaviour is governed by the tangential moment action which is considered to follow a constant distribution in the outer slab segment.

The elastic behaviour of the slab is assessed by accounting for the proportionality between the cracking load and rotation as a function of the cracking moment, composite radius $\left(r_{v}\right)$ and the elastic stiffness. Thereafter, the model employs bi-linear steel material laws, for both reinforcement bars and shear-heads, and a rigid-plastic material law for concrete. The post-cracking response of a hybrid member at an applied load level is estimated by assessing the stresses in the shear-heads $\left(\sigma_{v i}\right)$ and longitudinal reinforcement $\left(\sigma_{s i}\right)$ as function of the slab rotation $\left(\psi_{i, j}\right)$, strain profile and geometrical configuration, as expressed in Equation (1). Flexural response is assessed by considering linear strain compatibility between cross-sectional constituents is considered with yielding of the foremost reinforcing material subjected to tension (i.e. longitudinal bars).

$$
\sigma_{i}=E_{i} \psi_{i, j} \frac{d_{j}}{r_{i}}\left(1-\frac{c_{j}}{d_{j}}\right)
$$

For a hybrid sector $(H S)$, the stresses in the steel elements are estimated by relating the rotation $(\psi)$ to the slab radius $\left(r=r_{s}-r_{c}\right)$, and by accounting for the corresponding effective depth (Equation 2a,b). The steel insert is idealised as three reinforcement layers located at the centroids of the two flanges and web (Figure 9e). The forces in the shear-heads at the column face are determined separately for the three components and then summed up.

$$
\begin{gathered}
\sigma_{s r, k}=E_{s} \psi \frac{d}{\left(r_{s}-r_{c}\right)}\left(1-\frac{c_{c}}{d}\right) \leq f_{y s} \\
\sigma_{v i r, k}=E_{v} \psi \frac{d_{v, i}}{\left(r_{s}-r_{c}\right)}\left(1-\frac{c_{k}}{d_{v, i}}\right) \leq f_{y v}
\end{gathered}
$$

$$
\text { where } i=f t \text { (top flange), } f b \text { (bottom flange), } w \text { (web) }
$$

The radial forces acting on the wedge are the: radial force in the longitudinal bars at the column face $F_{s r}$, radial force in the longitudinal bars at the composite-to-concrete interface $d F_{s r}$, radial force in the shear-head $F_{v r}$ at the column face, forces produced by the slip between the shear-head and concrete slab $d F_{v \tau}$, and dowel force $F_{\text {dow }}$ (Equations 3a-d). The forces developed due to the slip between the steel profile and concrete body are estimated considering the area of the top flange and web of the steel profile, and bi-linear slip-stress laws. The maximum bond stress $\tau_{b v, \max }=0.5 \mathrm{MPa}$ that can develop between the two interfaces is assumed to be reached at a crack opening of $0.1 \mathrm{~mm}$ [29].

$$
\begin{aligned}
& F_{s r, k}=\sigma_{s r, k} \rho_{l} d \cdot r_{c} \Delta \phi \\
& \Sigma F_{v j r, k}=\Sigma\left(\sigma_{v j r, k} \rho_{v j} d_{v j}\right) \cdot r_{c} \Delta \phi \\
& d F_{s r, k}=\sigma_{s r, k} \rho_{l} d \cdot r_{v} \Delta \phi
\end{aligned}
$$




$$
d F_{v \tau, k}=\tau_{b v}\left(\psi_{k}\right) A_{v}
$$

For the tangential moment action, the hybrid sector is divided into a composite and a non-composite segment. The stresses in the reinforcement can be determined using Equations $(4 a, b)$. The forces acting on the rigid sectors are the tangential force acting in the composite segment $F_{s t, k}$ (where the neutral axis is determined with due account for the presence of the shear-head (Equation 5a)), and the tangential force acting in the RC sector $F_{s t, c}$ (Equation $5 \mathrm{~b}$ ). In the latter, conventional RC plastic equilibrium laws are adopted to assess the neutral axis position.

$$
\begin{gathered}
\sigma_{s t, k}=\sigma_{s r, k} \leq f_{y s} \\
\sigma_{s t, j}=E_{s} \psi \frac{d}{\left(r_{s}-r_{c}\right)}\left(1-\frac{c_{j}}{d}\right) \leq f_{y s} \\
\text { where } j=c, k \\
F_{s t, k}=\sigma_{s t, k} \rho_{l} d\left(r_{v}-r_{c}\right) \\
F_{s t, c}=\sigma_{s t, c} \rho_{l} d\left(r_{s}-r_{v}\right)
\end{gathered}
$$

The dowel force is derived from the moment equilibrium on the wedge around the centre of rotation, by accounting for the radial forces acting on the body and the radial component of the tangential force $F_{s t, k} \Delta \phi$. No shear-head radial forces act on the composite-to-concrete interface since the discontinuity plane is located outside of its tip. The shear-head forces estimated at the column face are required in order to obtain the dowel force acting on the outer slab segment (noncomposite) as represented in Equation (6).

$$
F_{d o w, k}\left(r_{v}-r_{c}\right)=\left(F_{s r, k}+F_{s t, k} \Delta \phi-d F_{s r, k}\right)\left(d-c_{k}\right)+\Sigma F_{v r, k}\left(d_{v, i}-c_{k}\right)-d F_{v \tau, k}\left(d-c_{k}\right)
$$

In the reinforced concrete sector $(R C S)$, the behaviour is similar to conventional RC elements due to the absence of the shear-head. The reinforcement stress is assessed by accounting for Equations $(7 \mathrm{a}, \mathrm{b})$. For the radial moment action, the forces contributing to the flexural capacity of the member are the steel radial forces $\left(F_{s r, c}\right.$ and $d F_{s r, c}$; Equations 8a,b), steel tangential forces $\left(F_{s t, c}\right.$; Equation 9) and dowel force $F_{\text {dow }}$ (Equation 10).

$$
\begin{aligned}
& \sigma_{s r, c}=E_{s} \psi \frac{d}{\left(r_{s}-r_{c}\right)}\left(1-\frac{c_{c}}{d}\right) \leq f_{y s} \\
& \sigma_{s t, c}=\sigma_{s r, c} \leq f_{y s} \\
& F_{s r, c}=\sigma_{s r, c} \rho_{l} d \cdot r_{c} \Delta \phi \\
& d F_{s r, c}=\sigma_{s r, c} \rho_{l} d \cdot r_{v} \Delta \phi \\
& F_{s t, c}=\sigma_{s t, c} \rho_{l} d\left(r_{s}-r_{c}\right) \\
& F_{d o w, c}\left(r_{v}-r_{c}\right)=\left(F_{s r, c}+F_{s t, k} \Delta \phi-d F_{s c, k}\right)\left(d-c_{c}\right)
\end{aligned}
$$


The radial moments acting on each hybrid $m_{r, k}$ and concrete $m_{r, c}$ sector are estimated by accounting for equilibrium at the centre of rotation (Equations 11a,b). The radial moments are constant over the wedge on the assumption that they do not develop in the outer slab sector. It was shown for RC flat slabs that the radial moment decreases nearly to zero outside the wedge region [14]. Surface strain records from the tests are in agreement with this for the RC sector, and show similar trends in the outer slab segment (non-composite) in the hybrid sector (Figure 10). The tangential moments are estimated by Equations (11c,d).

$$
\begin{gathered}
m_{r, k(\psi)}=d F_{s r, k(\psi)}\left(d-\frac{c_{k}}{2}\right)+d F_{d o w, k}\left(r_{v}-r_{c}\right) \leq m_{R, k} \\
m_{r, c(\psi)}=d F_{s r, c(\psi)}\left(d-\frac{c_{c}}{2}\right)+d F_{d o w, c}\left(r_{v}-r_{c}\right) \leq m_{R, c} \\
m_{t, k(\psi)}=F_{s t, k(\psi)}\left(d-\frac{c_{k}}{2}\right)+F_{s t, c(\psi)}\left(d-\frac{c_{c}}{2}\right) \leq m_{R, c} \\
m_{t, c(\psi)}=F_{s t, c(\psi)}\left(d-\frac{c_{c}}{2}\right) \leq m_{R, c}
\end{gathered}
$$

The in-plane geometrical distribution of the hybrid sectors can be evaluated with Equation (12), in which in-plane angle of one hybrid sector is defined by the tangential sector lines and the root of the shear-head at the column face (Figure 9a). The equilibrium condition for the hybrid axisymmetric model between moments acting on the slab and the applied force to the column is given by Equation (13).

$$
\begin{gathered}
\eta=8 \sin ^{-1}\left(0.5 b_{v} / r_{c}\right) \\
V(\psi)=\eta \pi\left(m_{r, k(\psi)} r_{v}+m_{t, k(\psi)}\left(r_{s}-r_{v}\right)\right)+(2-\eta)\left(m_{r, c(\psi)} r_{v}+m_{t, c(\psi)}\left(r_{s}-r_{v}\right)\right)
\end{gathered}
$$

At ultimate, the flexural strength of the hybrid member is reached when the plastic moment of each region is attained (Equation 14).

$$
V_{\text {flex }}=\pi\left(\eta \frac{r_{v}}{r_{s}} m_{R k}+\left(2-\eta \frac{r_{v}}{r_{s}}\right) m_{R c}\right) \frac{r_{s}}{r_{q}-r_{c}}
$$

Figure 11 depicts the rotational response of Specimen HS03-00. The strain level in the longitudinal reinforcement reached values beyond yield. The slab rotations, measured directly by the inclinometers, resulting from weak-axis moment action (i.e. N-S axis), indicated higher rotations in comparison with the orthogonal E-W rotation and the diagonal NW-SE. Considering an average value of the three recorded test rotations, the rotational responses for both the elastic and cracked regimes are captured faithfully by the axisymmetric model (Equation 13). The flexural strength of the member, assessed by means of Equation (13) accounting for full yielding of flexural reinforcement, or at ultimate by Equation (14), is estimated reasonably well. The ratio between the reported strength and that predicted is $V_{\text {test }} / V_{\text {flex }}=0.96$. The analytical results seem to show consistency with test results since the full flexural capacity was not reached during the tests, yet yielding in the longitudinal reinforcement was recorded. 
Equation (1) can be used to estimate the rotation of a flat slab as a function of the stress level in the longitudinal reinforcement, material characteristics and geometry of the cross-section. For RC flat slabs, considering idealised bi-linear response, the rotation can be assessed by the methods proposed by Muttoni [21] and Model Code 2010 [22]. Based on the two methods, the rotation is dependent on a section utilisation factor (i.e. $V_{i} / V_{\text {flex }}$ [21] or $m_{S} / m_{R}$ [22]; where $V_{i}$ is the ultimate test strength or design shear strength, $V_{\text {flex }}$ is the flexural strength, $m_{S}$ is the design bending moment and $m_{R}$ is the plastic moment) and an averaging factor that accounts for the neutral axis position (1.5 or 1.2 , depending on the method and level of refinement required).

Naturally, slab rotations in hybrid members show stiffer response than in conventional reinforced concrete. The rotational response of hybrid members is influenced by the geometrical characteristics (cross-section and embedment length) as well as the in-plane layout of shear heads (ratio between hybrid and RC sectors). The axisymmetric model presented in Section 4.1 accounts for the in-plane distribution of the shear-heads through the parameter $\eta$, whereas the influence of the embedment length is accounted for through the hybrid radius $r_{v}$. The influence of these parameters can be considered in a simplified manner by a factor $\lambda_{\psi}$ which is a function of the shear-head widthto-column width ratio $b_{v} / b_{c}$ and the embedment length-to-slab radius ratio $l_{v} / r_{s}$ (Equation 15a). Close assessment of the behaviour indicate that the flexural reinforcement plays a key role in the rotational response of such hybrid forms. In a simplified manner, the rotation at an applied load $V_{i}$ can be evaluated as a function of slab radius $r_{s}$, effective bending depth $d$, yield strength, elastic modulus of longitudinal reinforcement, and utilization factor $V_{i} / V_{\text {flex }}$ (Equation $15 \mathrm{~b}$ ).

$$
\begin{aligned}
& \lambda_{\psi}=2 \frac{b_{v}}{b_{c}}\left(\frac{r_{s}}{l_{v}}\right)^{300 \rho_{l}^{1.5}} \\
& \psi_{i}=\lambda_{\psi} \frac{r_{s}}{d} \frac{f_{y s}}{E_{s}}\left(\frac{V_{i}}{V_{f l e x}}\right)^{2}
\end{aligned}
$$

The rotational responses, as predicted by both the axisymmetric hybrid model (Equation 13) and bilinear hybrid model (Equation 15), are compared with those predicted by analytical models for RC flat slabs $[14,21]$ and with the experimentally recorded load-rotation diagram of Specimen HS0300 (Figure 11). It can be observed that the analytical models for conventional RC members cannot be used to predict the rotational response, nor the flexural strength. On the other hand, the proposed methods show good agreement with the test results.

In terms of implications on practical design, close examination of Equation (13) indicate that the increase in reinforcement from a low ratio of $\rho l=0.3 \%$ to a relatively high ratio of $\rho=2.0 \%$ would lead to about a five-fold enhancement in stiffness and strength. In contrast, possible increases in shear-head section sizes, for practical ranges of flat slab thicknesses, would have a comparatively insignificant influence on the stiffness and flexural strength. It appears therefore that the use of a high conventional reinforcement ratio in conjunction with small shear-head section sizes (e.g. $\rho=1.1 \%$ and HEB100) would be more effective than low reinforcement ratios combined with larger shear-head section sizes (e.g. $\rho=0.3 \%$ and HEB200).

To this end, it is worth noting that based on available test results, shear-heads with depth $h_{v}$ less than $d / 2$ could develop plastic deformations, which could lead to flexible behaviour of the steel 
insert [8]. This type of behaviour was not identified in fully integrated shear-heads in hybrid members as reported in the current study as well as other tests $[9,10]$. Hence, as a general guide that needs to be coupled with design checks, the shear-head depth should be at least $d / 2$, whilst the maximum shear-head depth would be limited by practical aspects including the slab thickness, size of longitudinal reinforcement and concrete cover. Importantly, an increase in shear-head embedment length produces stiffness enhancement due to the increase in radial moment capacity, but with an insignificant increase in flexural strength. For fully integrated shear-heads, the reinforcement typically yields first and governs the behaviour. Typical deformational response and flexural strength as a function of the embedment length-to-slab radius $l_{v} / r_{s}$ ratio, points to a more effective use of short-to-intermediate rather than long shear-heads. Accordingly, embedment lengthto-slab radius ratios outside the range of $l_{v} / r_{s}=0.2-0.4$ should be avoided in design since, apart from the lack of test data, they appear less effective and practical.

\section{Punching Shear Strength}

\subsection{Members without shear reinforcement}

\subsubsection{Kinematics and failure modes}

Punching shear failures in conventional RC flat slabs are instantaneous and characterized by dislocation of a conical surface from the flat slab. Before failure, the forces are transferred from the column to the slab through a tri-dimensional strut that develops at variable inclination angles from the root of the column to the tension reinforcement, as a function of the slab thickness, flexural characteristics and material strengths [30]. High stress levels in the strut activate inclined cracking that eventually leads to failure. In isolated specimens, the force transfer is also influenced by the span ratios and boundary conditions. Previous investigations by the authors on one-way hybrid members [29] showed that the force transfer between the shear-head and RC elements is mobilised through an inclined strut that is supported on the bottom flange of the shear-head. Shear failures occurred in hybrid one-way members due to the extension of a governing shear crack that developed below the strut and the bottom tip of the shear-head. Experimental observations reported in Section 3 indicate that in the case of hybrid flat slab members, the shear transfer and sheargoverned failures develop in a similar manner.

Figure 10a depicts the strain profiles recorded by means of surface gauges for Specimen HS13-00. The radial strain profiles on the top face of the slab (Figures 10a,b) indicate high peaks at the shearhead tip in the hybrid sector (normal direction, Gauges $\mathrm{kA}_{\mathrm{A}}-\mathrm{kD}_{\mathrm{D}}$ ) and at the column face in the RC sector (diagonal direction, Gauges $\mathrm{c}_{\mathrm{A}}-\mathrm{c}_{\mathrm{D}}$ ) (Figure 10c). The concrete tangential strains are shown in Figure 10d. This shows that inclined cracking initiated in the hybrid sector and eventually spread to the RC sector. As the inclined crack propagated towards the compression zone, it produced an instantaneous punching shear failure. Before failure, the neutral axis in the hybrid sector developed a geometrical elbow-shaped pattern suggesting that the punching shear crack passed below the lower flange of the shear-head (Figure 12a).

In the RC sector, the neutral axis position indicated nearly constant distribution, both in the column vicinity and at the composite-to-concrete interface, suggesting a crack pattern such as that 
illustrated in Figure 12b. Failure was characterized by the dislocation of a conical body, consisting of the shear-head assembly and surrounding concrete. The failure surface was characterized by an octagonal shape that, on the top face, is located at about $1.0 \mathrm{~d}$ from the tip of the shear-head (Figure 4). The crack pattern obtained through cross-sectional saw cuts on specimens without transverse reinforcement (HS13-00, HS13-C0, HS07-C0 and HS03-00; see Figure 5), indicate close correlation with the recordings by the surface gauges (Figure 10) and the qualitative force transfer in Figure 12. This suggests that the critical shear region for members without transverse reinforcement corresponds to the composite-to-concrete interface in the hybrid sector.

The tests reported in Sections 2 and 3 (HS13-00, HS13-C0, HS03-00 and HS07-C0) as well as previous investigations carried out at Imperial College [8] and tests available in the literature [9, 10] indicate a high dependency between the punching crack pattern on the top face of the slab and the embedded length of the shear-head. The ratio between the embedment length $l_{v}$ and the radial crack length $l_{c r}$, (Figure 12), represented by the in-plane distance between the column face and the punching shear crack at the intersection with the flexural reinforcement, is in the range $l_{c r, k} / l_{v}=1.00$ 2.04 (average of 1.38) in the hybrid sectors and $l_{c r, c} / l_{v}=0.74-1.90$ (average of 1.30) in the RC sectors. This corresponds to an average distance of $3.12 d$ from the column face in the hybrid sectors, and $2.80 d$ in the RC sectors - which is higher than typically seen in RC flat slabs (1.0 $2.0 d$ ). This indicates that the presence of shear-head translates the failure surface outside the shearhead region.

\subsubsection{Critical section and perimeter}

Existing codified provisions for $\mathrm{RC}$ flat slabs require the definition of a control perimeter, dependent on the location of the critical shear region, to evaluate the punching shear strength of a member [16, 22, 28]. In the case of members provided with shear-heads, the critical section located within the critical shear region is dictated by the governing strut support location and its inclination. These are primarily dependent on the shear-head length-to-slab radius ratio $l_{v} / r_{s}$ (as described in Section 5.1.1) and influenced by its shape and cross-section. For the test specimens described in Section 2, electrical strain gauge records showed that, on average, the strut is supported at about $0.90 l_{v}$ from the column face (Figure 12).

Figure 13 depicts the relationship between the critical crack length-to-shear-head embedment length ratio $l_{0} / l_{v}$, and the embedment length-to-slab radius ratio $l_{v} / r_{s}$ (corresponding to the weak-axis rotation). It can be observed that, for short shear-heads, the critical section is located further away from the composite-to-concrete interface compared to the case of long shear-heads (where it is located near the interface; e.g. $l_{v} / r_{\mathrm{s}}=0.5$ corresponds to $\left.l_{c r} / l_{v}=1\right)$. This suggests that for short shearheads, in isolated members, the governing strut develops at flatter inclination angles than in the case of long shear-heads, and the dependency between the embedment length and the location of the critical shear section varies accordingly.

Based on experimental observations and top crack patterns observed in the current and previous studies for hybrid members without shear reinforcement [8, 11], a method to determine the approximate location of the critical section is proposed below. The relationship between the crack pattern and embedment length can be approximated by Equation (16). Considering that $d_{0}$ is the vertical projection of the strut supported by the bottom flange of the shear-head, its length and 
inclination can be estimated by Equations (17) and (18), respectively. Consequently, the location of the critical section can be determined by Equation (19), where $l_{0}$ is considered from the column face (Figure 12).

$$
\begin{aligned}
& \frac{l_{c r}}{l_{v}}=\frac{2}{3} \sqrt{\frac{r_{s}}{l_{v}}} \\
& d_{0}=d-d_{v f b}-t_{f} / 2 \\
& \theta_{s t r}=\sin ^{-1} \frac{d_{0}}{l_{v}\left(0.67 \sqrt{r_{s} / l_{v}}-1\right)} \\
& l_{0}=l_{v}\left(\sqrt{r_{s} / l_{v}}+1.5\right) / 3
\end{aligned}
$$

Elastic finite element analyses were carried out to investigate the shear force distribution and flow within the hybrid members investigated herein. This enabled an assessment of the location of the critical section as well as the length of the control perimeter $b_{0}$, noting that Model Code 2010 allows the calculation of a shear-resisting control perimeter $b_{0}$ in a general case on the basis of shear fields [22]. The perimeter $b_{0}$ resulted from the applied load $V_{i}$ as a function of the maximum value of the projection of the elastic shear force $v_{\text {perp, max }}$ perpendicular to the control perimeter $\left(b_{0}=V_{i} / v_{\text {perp, } \max }\right)$.

The shear forces per unit width $v_{x}$ and $v_{y}$ were obtained from elastic models that adopted four-noded shell elements. The FE model replicating the $2.2 \mathrm{~m}$ by $2.2 \mathrm{~m}$ HS13-00 test specimen were meshed with $5 \mathrm{~mm}$ element sizes to enable accurate assessment of slab shear forces. The position of the supports followed that shown in Figure 2, and the applied load distribution was determined from electrical strain gauge measurements at ultimate. It was assumed that the load acts on the shearheads along their centres for the longitudinal direction. This simulates a load transfer through struts supported by the bottom flanges at their intersection with the shear-head webs.

The qualitative distribution $\left(V / V_{\max }\right)$ of the applied load is based on the strains recorded in the tests and integrated over the cracked cross section. Figure 14a depicts the shear force distribution relative to the embedment length, as an average of the forces acting on the North and West shear-heads in Specimen HS13-00. It was observed that shear forces decreased in a stable manner, with about $25 \%$, as the shear-head length increased. The shear fields resulting from the linear elastic finite element analysis are shown in Figure 14b. The shear equilibrium at any location is ensured by the two orthogonal components ( $v_{x}$ and $v_{y}$ ) resulting in one principal direction for the shear $v_{\text {perp,max. The }}$ force flow is plotted using vector fields that follow the principal direction. The direction of forces is plotted using arrowheads overlapped over the principal flow lines, and grayscale intensity maps are used as background to emphasize the regions where the peak shear forces are located.

The shear fields in Figure 14b indicate a nearly symmetric distribution of forces around the column and shear-heads. The magnitude of principal shear tends to increase in the hybrid sector at the shear-head tips and has lower intensity in the RC sector (i.e. diagonals of the slab). The shear flow illustrates paths characterized by direct transfer from the shear-head ends to the supports. The maximum perpendicular shear force per unit width $v_{\text {perp, max }}$ is located in the hybrid sector at the transition between the composite and non-composite segments (Figure 14b). The finite element results indicate a maximum perpendicular shear force per unit width $v_{\text {perp, max }}$ of $289 \mathrm{kN} / \mathrm{m}$ at the in- 
plane location of the critical section. Considering that the ultimate punching shear strength of Specimen HS13-00 was $V_{\text {test }}=1005 \mathrm{kN}$, the length of the control perimeter is evaluated as $b_{0}=$ $3478 \mathrm{~mm}$.

On the basis of the dependency between the shear-head embedment length and critical section location, the control perimeter for punching shear calculations can be expressed as a function of critical length $l_{0}$. The perimeter resulting from shear fields analysis is similar to the control perimeter estimated with Equation (20a), which is graphically defined for each shear-head by an arc length with a radius equal to the in-plane strut projection $d_{0}$ plus two critical lengths $l_{0}$ (Figure 15). For Specimen HS13-00, the value bo, assessed by means of Equation (20a) is $3431 \mathrm{~mm}$, which is similar to the value obtained from shear field analysis.

For short shear-heads, the diagonal lines of the control perimeter extending from the shear-head tip region could join, resulting in a closed shape of the critical perimeter. Considering square columns, the length of a closed control perimeter can be estimated by Equation (20b). The critical perimeter used for assessing the punching shear strength is the minimum resulting from Equations (20a) and (20b).

$$
\begin{aligned}
& b_{0, a}=\pi d_{0}+8 l_{0} \\
& b_{0, b}=\pi d_{0}+4\left[l_{0}+\left(b_{c}-b_{v}\right) / 2\right] \sqrt{2} \\
& b_{0}=\min \left(b_{0, a}, b_{0, b}\right)
\end{aligned}
$$

where $l_{0}$ is the distance representing the location of the critical section, given in Equation (19).

\subsubsection{Prediction of shear strength}

This section deals with the assessment of the punching shear strength of hybrid steel column-to-flat slab members without shear reinforcement. The experimental and analytical findings in this paper enable strength predictions considering three levels of refinement. Primarily, the fundamentals of the Critical Shear Crack Theory (CSCT) combined with the shear-head dependent definition of the the control perimeter $b_{0}$ (Equation 20) are employed for the 'detailed and simplified assessment approaches' for strength predictions. The method evaluates the punching shear strength of flat slabs without shear reinforcement by accounting for the intersection between the deformational response of the slab $(V-\psi)$ and the failure criterion adopted within the approach (Equation 21 - in which $\psi$ is the hybrid slab rotation, $d$ is the effective bending depth, and $d_{g}$ and $d_{g 0}=16 \mathrm{~mm}$ are the maximum and reference aggregate sizes, respectively) [21]. The rotational response is determined by means of the axisymmetric hybrid model (Equation 13) for the 'detailed approach' and the bi-linear hybrid model (Equation 15) for the 'simplified approach'. On the basis of the results of the two previous approaches, simplified 'analytical design expressions' are further derived using the bi-linear rotational model (Equation 15), shear-head dependent definition of the control perimeter (Equation 20) and the Model Code $2010 k_{\psi}$ factor [22]. Comparative assessments, using the findings from this investigation as well as other relevant test results available in the literature [8-11], are carried out against existing codified provisions [16, 22, 28]. 
Equation (14) was employed to assess the flexural strength of the four hybrid specimens without shear reinforcement as examined in Section 3, together with the tests reported by Eder et al [8], Lee et al [9] and Kim et al [10]. This indicated that only one of the specimens failed in flexure whilst all the others failed in punching shear. Values of $V_{\text {test }} / V_{\text {flex }}$ ratio above unity identify flexural failures, whereas those below unity identify punching shear failures. Table 4 summarises the failure mode and details of the members considered. All specimens had square slabs with square or nearly square columns having a side ratio $b_{c 1} / b_{c 2} \sim 1.00$. Various geometrical dimensions, loading arrangement, and material properties were employed. The thickness of slabs varied in the range of $h=155-300$ $\mathrm{mm}$, column sides of $b_{c}=180-500 \mathrm{~mm}$, conventional reinforcement ratio $\rho_{l}$ of $0.33-1.47 \%$, and incorporated one or two cruciform shear-heads with embedment lengths in the range $l_{v}=200-770$ $\mathrm{mm}\left(l_{v} / r_{s}=0.1-0.4\right)$.

$$
k_{\psi}=0.75 /\left[1+15 \cdot \psi \cdot d /\left(d_{g 0}+d_{g}\right)\right]
$$

Figure 16 depicts the rotational response and the punching shear strength of Specimens HS13-00, HS13-C0, HS07-C0 and HS03-00. The rotational response, captured faithfully for both low conventional reinforcement ratios $\left(\rho_{l}=0.33 \%\right.$ for HS $\left.03-00\right)$ and relatively high ratios $\left(\rho_{l}=1.37 \%\right.$ for HS13-00), intersected with the failure criterion (Equation 21), is in good agreement with the test results. Both the 'detailed assessment approach' and the 'simplified assessment approach' estimate reasonably well the punching shear strength of the four specimens without shear reinforcement, with an average of average $V_{\text {test }} / V_{\text {calc }}=1.02$ and $\mathrm{COV}=0.08$, and average $V_{\text {test }} / V_{\text {calc }}=1.02$ and $\mathrm{COV}=0.07$, respectively for both approaches. This points to the validity of the assumptions employed for determining the location of the critical section, based on which further simplifications can be considered for design purposes.

Punching shear strength of a hybrid flat slab provided with shear heads and without stud shear reinforcement, can be estimated using the simplified 'analytical design expressions' proposed here (Equations 22a,f) that adopt the fundamentals of Model Code 2010 (Equations 22a,b), and accounting for shear-head dependent parameters such as its length, geometry and depth in the crosssection. The rotational response factor $k_{\psi}$ Equation (22b) is dependent on the hybrid slab rotation $\psi$ (as presented in Section 4.3 and Equation 22c) at $V_{i}$ (ultimate test punching shear strength or design punching shear force), flexural effective depth $d$ and aggregate size $d_{g}$. The effective depth used for punching shear calculations $d_{0}$ is a function of the effective bending depth $d$ and depth of the shearhead in the cross-section (Equation 22d). The length $b_{0}$ of the critical perimeter, discussed before in detail in Section 5.1.2, can be determined using Equations (22e,f).

$$
\begin{aligned}
& V_{c}=k_{\psi} \sqrt{f_{c}} b_{0} d_{0} \\
& k_{\psi}=1 /\left(1.5+0.9 \cdot \psi \cdot d \cdot k_{d g}\right) \\
& \psi=2 \frac{b_{v}}{b_{c}}\left(\frac{r_{s}}{l_{v}}\right)^{300 \rho_{l}^{1.5}} \cdot \frac{r_{s}}{d} \frac{f_{y s}}{E_{s}}\left(\frac{V_{i}}{V_{f l e x}}\right)^{2} \\
& d_{0}=d-d_{v f b}-t_{f} / 2 \\
& b_{0}=\min \left(\pi d_{0}+8 l_{0} ; \pi d_{0}+4\left[l_{0}+\left(b_{c}-b_{v}\right) / 2\right] \sqrt{2}\right)
\end{aligned}
$$




$$
l_{0}=l_{v}\left(\sqrt{r_{s} / l_{v}}+1.5\right) / 3
$$

In terms of codified guidance, no specific provisions are given in Eurocode 2 [28] to assess the punching shear strength of members with shear-heads. The punching shear strength of conventional RC flat slabs without shear reinforcement and without pre-stressing can be evaluated by Equation (23a). This is dependent on the size effect $\left[1+(200 / d)^{1 / 2}<2.0\right]$, flexural reinforcement ratio $\rho_{l}$, concrete strength $f_{c}$, effective depth $d$ and control perimeter $b_{0}$ situated at $2 d$ from the column face (Equation 23a,b). Test results reported in previous studies [3, 7] for RC flat slabs show that the presence of a shear-head shifts the critical zone outside the shear-head region, exhibiting behaviour similar to that of flat slabs supported by larger columns. Hence, the strength assessment of hybrid members with shear-heads and without shear reinforcement can be comparable to the verification for failure outside of the shear reinforced region for members provided with transverse bars. The control perimeter accounts for a rounded control section situated at $k d$ from the shear-head tip $(k=1.5)$ extended in both sides of the shear-head with a distance of $1.0 d$ (Figure 17a).

$$
\begin{gathered}
V_{c}=0.18(1+\sqrt{200 / d})\left(100 \rho_{l} f_{c}\right)^{1 / 3} b_{0} d \\
b_{0}=2 d(k \pi+4)
\end{gathered}
$$

The American guidelines ACI318-14 [16] are largely based on the design procedure proposed by Corley and Hawkins [3] in which the punching shear strength is determined using Equation (24a). The critical slab section for punching shear calculation intersects each shear-head at three-quarters the distance $0.75 l_{v}$ from the column face to the end of the shear-head, but not closer than $d / 2$ from the column face (in this investigation $l_{v}$ is the distance from the column face). The in-plane layout of the control perimeter for hybrid members is depicted in Figure $17 \mathrm{~b}$.

$$
\begin{aligned}
& V_{c}=0.33 \sqrt{f_{c}} b_{0} d \\
& b_{0}=4 b_{v}+4\left[\frac{3}{4} l_{v}+\left(\frac{b_{c}-b_{v}}{2}\right)\right] \sqrt{2}
\end{aligned}
$$

In Model Code 2010, the punching shear strength of RC flat slabs is assessed by considering Equation (25a) using a conservative $k_{\psi}$ factor (Equation 25b) which is dependent on the slab rotation $\psi$, effective bending depth $d$ and a $k d g$ parameter (Equation 25c) as a function of maximum aggregate size $d_{g}$. For Level II Approximation, the rotation of a RC slab at a specific shear force is given by Equation (25d) (where $m_{s}$ is the design bending moment, $m_{R}$ is the plastic moment of a RC cross-section and $r_{s}$ is a function of the member moment span - Equation 25e). The approach incorporates a critical perimeter that is dependent on the shear-head geometry and governing strut support type. The critical section is situated at $d_{0} / 2$ from the strut support (Equation $25 \mathrm{f}$ and Figure $17 \mathrm{c})$. The section utilisation factor $m_{s} / m_{R, a v g}$ can be estimated using Equation $(25 \mathrm{~g})$ for the case when no eccentricity is acting on the member. The average plastic moment that is estimated as a function of the in-plane geometry of the shear-head, concrete plastic and composite plastic moments (Equation 25h).

$$
\begin{aligned}
& V_{c}=k_{\psi} \sqrt{f_{c}} b_{0} d_{0} \\
& k_{\psi}=1 /\left(1.5+0.9 \cdot \psi \cdot d \cdot k_{d g}\right)
\end{aligned}
$$




$$
\begin{aligned}
& k_{d g}=32 /\left(16+d_{g}\right)>0.75 \\
& \psi=1.5 \frac{r_{s}}{d} \frac{f_{y s}}{E_{s}}\left(\frac{m_{s}}{m_{R, a v g}}\right)^{1.5} \\
& r_{s}=0.22 B \\
& b_{0}=4\left(b_{v}+3 d_{0}\right) \\
& m_{s}=V_{\text {test }} / 8 \\
& m_{R, \text { avg }}=(1-\eta / 2) m_{R, c}+\eta\left(m_{R, c}+m_{R, k}\right) / 4
\end{aligned}
$$

Table 5 summarises the punching shear strength prediction results from the 'detailed' and 'simplified' assessment approaches, 'analytical design expressions' considered in this study, together with those obtained from codified approaches as discussed above. The results are reported as ratios between the test strength $V_{\text {test }}$ and estimated strength $V_{\text {calc }}$ (Equations 13-25). Values of $V_{\text {test }} / V_{\text {calc }}$ above unity depict conservative predictions, whereas below unity represent unconservative estimates.

As indicated in Figure 18a, the modified assumptions regarding the definition of the control perimeter, as described previously for Eurocode 2, show conservative predictions with an average of 1.59 and a $\mathrm{COV}$ of 0.16 , with a tendency for over-estimating the strength for relatively long shear-heads. ACI318 strength assessments (Figure 18b) give an average of 0.99 (with a COV of $20 \%$ ) between the punching shear strength obtained from tests and those predicted by Equations (23). The influence of the embedment length of the shear-head is captured reasonably well, with a slight tendency of under-estimation of the capacity for long shear-heads. On the other hand, as depicted in Figure 18c, Level II of Approximation of Model Code 2010 shows the largest scatter primarily because a key parameter in the method is the rotation of the slab, which is estimated in a simplified manner by Equation (25d) validated for conventional RC flat slabs. Moreover, the use of an effective depth dependent critical perimeter $b_{0}$ rather than on the shear-head embedment length leads to overly-conservative estimates when the method is applied to hybrid members, particularly with the increase in embedment length.

As depicted in Figure 18d, the results of the 'detailed assessment approach', in which the rotational response is assessed by the means of the axisymmetric hybrid model (Equation 13) is intersected with the failure criterion (Equation 21) [21] and considers a shear-head dependent control perimeter (Equation 20), are in close agreement with a $V_{\text {test }} / V_{\text {calc }}$ ratio of 1.01 and a COV of $5 \%$. The use of the 'simplified assessment approach', in which the load-rotation relationship, assessed by means of the bi-linear hybrid model (Equation 15), is intersected with the failure criterion in Equation (21), and accounts for a shear-head dependent critical section, also leads to close estimates with $V_{\text {test }} / V_{\text {calc }}$ ratio of 1.01 and a $\mathrm{COV}$ of $8 \%$, as shown in Figure 18e. This indicates that both the detailed and simplified assessment approaches can predict accurately the ultimate strength, for both low and high embedment length-to-slab radius ratios. Finally, as indicated in Figure $18 \mathrm{f}$, the simplified 'analytical design expressions' presented in Equations (22a-f), which consider the MC2010 $k_{\psi}$ parameter [22], hybrid slab rotation $\psi$ (assessed by means of the bi-linear model in Section 4.3) and the shear-head dependent critical section (discussed in Section 5.1.2), offers reasonably good agreement with the test results with an average $V_{\text {test }} / V_{\text {calc }}$ of 1.04 and COV of 0.16 . This therefore 
offers a simple and practical approach for design purposes, whilst achieving more reliable prediction levels compared to existing code procedures.

\subsection{Members with transverse shear reinforcement}

\subsubsection{Kinematics and failure modes}

In conventional RC flat slabs, the presence of transverse reinforcement can increase the ultimate punching shear strength. In this case, possible failure modes include: (i) failure within the shear reinforced region $\left(V_{R, \text { in }}\right)$ in which the critical crack intersects transverse bars, (ii) failure outside the shear reinforced region $\left(V_{R, \text { out }}\right)$ in which the critical surface does not cross the shear reinforcement, and (iii) due to strut crushing (located between the column face and first reinforcement perimeter $\left.V_{R, \max }\right)$. The governing failure mode is dictated by the transverse reinforcement layout and amount. In design, the punching shear strength is the minimum of the three $V_{R}=\min \left(V_{R, i n}, V_{R, o u t}, V_{R, \max }\right)$. Flexural failure could govern if yield occurs in the longitudinal reinforcement prior to yielding of the transverse bars.

In the case of hybrid members provided with shear reinforcement, the behaviour at ultimate is expected to be similar to that in conventional RC members (Figure 19). Experimental observations reported in Section 3 indicate that stud shear reinforcement added to hybrid members with shearheads enhance the strength and ductility. Also, as for hybrid members without shear reinforcement, the shear-head translates the failure region away from the column vicinity (Section 5.1). For Specimens HS13-0T and HS13-CT, the increase in ductility is primarily attributed to the postelastic response of the flexural bars, whereas the strength increase results from the activation (i.e. yield and potential fracture) of a number of transverse bars intersected by the critical crack (Figures 7 and 8), with failure occurring due to punching shear within the shear reinforced region, with the shear-head remaining elastic.

Similar to slabs without transverse reinforcement, the strain profiles in the radial direction of the hybrid sector recorded high peaks at the shear-head tip, indicating that the critical section is located at the composite-to-concrete interface (as discussed in detail in Section 5.1.2). The neutral axis position recorded at failure, by means of strain integration over the cross-section, showed a drop from the column face to the shear-head tip. This suggests that the punching shear crack initiates in a similar manner as for the hybrid slabs without transverse reinforcement. Failure initiates in the hybrid sectors at the composite-to-concrete interface and further propagates towards the conventional RC sectors (i.e. diagonals of the slab), while activating several transverse bars.

Figure 20 shows that the failure surfaces of the two test specimens differ. For HS13-CT, the continuity plate offered a more stable strut support ensuring a smoother force transfer between the column and slab (Figure 20a), whereas for HS13-0T, without continuity plate, the qualitative force transfer depict a more intricate path that produced distributed shear cracking (Figure 20b). Based on the observations reported in Section 3.2, the number of studs activated by the punching shear crack for Specimen HS13-0T was twenty four. For Specimen HS13-CT, which exhibited the highest capacity, the crack pattern showed a more localised failure with punching shear cracks that originated from the shear-head bottom flange and intersected at least twenty eight transverse studs. 


\subsubsection{Prediction of shear strength}

The axisymmetric rotational model from Section 4.1 is used herein, in conjunction with the fundamentals of the CSCT approach [21,26] and relevant shear-head dependent parameters, for strength predictions of Specimens HS13-0T and HS13-CT through the detailed assessment approach'. On the other hand, in the 'simplified assessment approach', the load-rotation response is idealised through a bi-linear representation, with other assumptions maintained. Additionally, 'analytical design expressions', primarily based on Model Code 2010 [22], are proposed for predicting the punching shear strength of hybrid flat slabs provided with shear-heads and with transverse reinforcement. Finally, current design procedures are employed for comparison [16, 22, 28]. These consider the punching shear strength of flat slabs with shear reinforcement based on the cumulative contributions of the concrete and transverse bars (Equation 26a). In some cases, the concrete contribution is reduced in the presence of transverse reinforcement using a modification factor (represented here by $\lambda$ ). EC2 reduces the contribution by $25 \%(\lambda=0.75)$; ACI318 reduces it by $50 \%(\lambda=0.50)$, whereas the Model Code considers the full concrete contribution $(\lambda=1.00)$. In this investigation, the contribution of the shear reinforcement is considered in full $(\lambda=1.00)$ for strength assessments with the 'detailed and simplified approaches', the 'analytical design expressions' and as well as the Model Code 2010, whereas reduced contribution is used for assessments with EC2 and $\operatorname{ACI} 318$ ( $\lambda=0.75$ and $\lambda=0.50$, respectively).

In the detailed and simplified assessment approaches for hybrid members, the concrete contribution, is estimated by intersecting the failure criterion from Equation (21) [21] with the load-rotation curve of the slab (Equations 13 and 15, respectively). The contribution of the transverse reinforcement (Equation 26b), that is a function of the amount of bars intersected by the failure surface (as discussed in Section 3.2 and illustrated in Figure 8), is determined by considering that the opening of the shear critical crack is proportional to the product of the rotation of the slab and the effective depth of the member, where $\kappa=0.5$ (Equation 26c) [26]. The minimum amount of bars intersected by the failure surface considered in assessments is $n_{b w}=24$ for HS13-0T and $n_{b w}=28$ for HS13-CT. The stress in the transverse reinforcement is a function of the crack opening $w_{\text {cr, }}$ reinforcement geometry and type, and bond conditions between the concrete and the rebar. The behaviour of the double headed stud rail reinforcement system is characterized by three regimes depending on the crack width and the stud location relative to the tip of the crack.

$$
\begin{aligned}
& V_{R, \text { in }}=\lambda V_{c}+V_{s} \\
& V_{s}=\Sigma A_{s w} \sigma_{s w}\left(w_{c r}, f_{b}\right) \\
& w_{c r}=\kappa \cdot \psi \cdot d
\end{aligned}
$$

Figure 21 depicts the load-rotation response of Specimens HS13-0T and HS13-CT, as well as the flexural and punching shear strength predictions considering Equations (14) and (26a), respectively. The ultimate test strength to flexural strength $V_{\text {test }} / V_{\text {flex }}$ ratios indicate values below unity $\left(V_{\text {test }} / V_{\text {flex }}\right.$ $=0.92$ for HS13-0T; $V_{\text {test }} / V_{\text {flex }}=0.97$ for HS13-CT), suggesting that flexural failure did not govern . The predicted rotational response shows softening after the opening of the punching shear crack, which is mainly due to the presence of high amounts of transverse reinforcement that enhance member stiffness, a phenomenon not accounted for in the hybrid axisymmetric model in Section 4. 
However, a more flexible load-rotation curve, intersected with the cumulative contributions of concrete and shear reinforcement, results in conservative strength estimates (Table 6). This gives an average between the estimated and test strengths of 1.06 with a COV of $1 \%$, which illustrates the effectiveness of the hybrid axisymmetric model and also supports the amount of studs considered to be activated by the critical crack.

In order to enable a more realistic assessment of the punching shear strength of hybrid steel column/flat slab members with shear-heads and provided with stud transverse reinforcement, Equations (22a-f) are linked with Model Code 2010 Equations (27a,b). For RC flat slabs, these consider a rotational dependent contribution of the shear reinforcement to the punching shear strength, multiplied by a $k_{e}$ factor that depends on the eccentricity (assumed as $k_{e}=1.0$ herein). The stress in the reinforcement is a function of the slab rotation $\psi$, reinforcement yield strength and elastic modulus, transverse bar diameter $d_{b w}$ and design bond strength $f_{b d}$ (assumed as $3 \mathrm{MPa}$ in this investigation) (Equation 27a,b). In case of hybrid members (HS13-0T and HS13-CT), provided with shear-heads and with stud shear reinforcement, the slab rotation is a function of the shear-head configuration (Equation 22c), and the punching shear strength is evaluated based on the cumulative contributions of concrete and shear reinforcement (Equation 26a).

The shear reinforcement contribution is dependent on the layout, amount of transverse bars as well as on the shape of the failure surface. Codified provisions do not offer guidance on the amount of bars that should be considered in calculations for members provided with shear-heads. Hence, the minimum amount of bars intersected by the failure surface are considered ( $n_{b w}=24$ for HS13-0T and $n_{b w}=28$ for HS13-CT). For Eurocode 2, the shear reinforcement contribution is given by Equation (27c). It accounts for one row of transverse bars $A_{s w}$ located in the vicinity of the RC column, their yield strength $f_{y s w}$ (limited to $f_{y s w}=250+0.25 d$ ), their inclination in relation to the slab plane, and a ratio that accounts for the effective depth $d$ and bar spacing $S_{w}$. In the case of ACI318, the contribution is dependent on the amount of bars that intersect a potential punching plane at $d / 2$ from the strut base. Their yield strength is limited to $f_{y s w}=420 \mathrm{MPa}$ (Equation 27d). The effective yield strength $\left(f_{y s w}=566 \mathrm{MPa}\right)$ of the $10 \mathrm{~mm}$ studs is accounted for in MC2010.

$$
\begin{aligned}
& V_{s}=\sum A_{s w} \sigma_{s w} k_{e} \\
& \sigma_{s w}=\frac{E_{s} \psi}{6}\left(1+\frac{f_{b d}}{f_{y s w}} \frac{d}{d_{b w}}\right) \leq f_{y s w} \\
& V_{s}=A_{s w} f_{y s w} \sin \left(\beta_{w}\right)\left(1.5 d / s_{w}\right) \\
& V_{s}=A_{s w} f_{y s w}\left(d / s_{w}\right)
\end{aligned}
$$

Table 6 depicts the slab configuration and transverse reinforcement details as well as the ultimate flexural and test strengths. Table 7 and Figure 21 give the strength predictions resulting from the 'detailed assessment approach' (Equations 13, 20, 21, 26), the simplified assessment approach' (Equations 15, 20, 21, 26), the proposed 'analytical design expressions' based on the Model Code 2010 approach (Equations 22a-f, 26a, 27a,b) as well as the codified provisions. Overall, the strength predictions of the detailed as well as simplified assessment approaches provide reliable results. In the case of the detailed method, the average test-to-prediction strength ratio is 1.06 (with 
$\mathrm{COV}=0.01$ ), whereas for the simplified method the ratio is 1.08 (also with $\mathrm{COV}=0.01$ ). The proposed analytical design expressions, which consider shear-head dependent factors for strength predictions, result in an average ratio of 1.09 and a similarly low COV of 0.01 .

Reduction of the yield strength of the transverse reinforcement and of the concrete contribution seems to offer close agreement with the test results for Eurocode 2 strength predictions (average ratio of 1.01 and $\mathrm{COV}$ of 0.03 ). The equations of $\mathrm{ACI} 318$, combined with the assumptions noted before regarding the amount of shear reinforcement, seem to result in unconservative estimates (average ratio of 0.90 ). On the other hand, assessment of slab rotation based on typical RC design shows over conservative predictions in the case of Model Code 2010 Level II (average ratio of 1.45), due to the consideration of an unrealistically flexible member response. The suggested 'analytical design expressions' therefore represent an equally reliable approach to the detailed and simplified assessment methods, which is suitable for effective practical application and reflects more realistically the physical characteristics of key geometric and material parameters.

Further to the discussions presented in Section 4 on practical design considerations, the shear-head embedment length should ideally be determined in accordance with the shear force demand in the hybrid sector. As discussed in Section 5.1.2, the bottom flange acts as support for struts that transfer the load from the steel column to the RC flat slab. The shear force demand should be less than the slab punching shear strength at the governing strut support location (i.e. 0.9 $l_{v}$ in Figure 12a). Considering a force transfer as indicated in Figures 12a and 20, the width of the shear-head dictates the cross-sectional strut thickness and, consequently, the amount of shear transferred. In order to allow a smooth force transfer, the bottom flange should be relatively stiff and at least $b_{v}>d / 2$ wide based on test ranges considered in this study and previous research [8-11]. The provision of stiffener plates at the level of the shear-heads between the column web and the thick plates welded to the column flanges would also ensure a smooth and symmetric in-plane force transfer between the shear-heads and the flat slab by limiting the out of plane deformation of the column panel.

On the other hand, shear-head configurations containing continuity plates around the column could be beneficial for members with transverse reinforcement, as it could shift the critical moment region away from the column face and could also help stabilise the ultimate shear behaviour since they act as support for force-transferring struts to the transverse bars. However, the continuity plates are less effective, in terms of influence on both stiffness and strength, for members without shear reinforcement, since for relatively stiff shear heads, the critical shear region is located at the composite-to-concrete interface. Due to the instantaneous nature of the shear governed failure and its initiation in the critical shear region, the struts supported by the continuity plate that could carry supplementary load become ineffective as the force transfer paths are obstructed by the discontinuity produced by the punching shear crack.

For members with transverse reinforcement, the shear cracks generally develop under governing struts that originate from the bottom flanges of the steel profile at inclination angles of about $45^{\circ}$. Hence, the critical regions are located within $d_{0}$ distance from the shear-head web. This shows that the shear reinforcement that contributes to the punching shear strength, with failure occurring within the shear reinforced region, is the amount that is located in the shear-head vicinity, at 0.3$0.7 d_{0}$ from the flange edges (Figure 22a). In isolated specimens, the crack angles might vary as they depend on the in-plane geometry of the slab and that of the shear-head as well as the position of the supports. For short distances between the shear-head tip and slab supports, the direct strutting effect 
could govern the behaviour leading to flatter inclination angles. In this case, the amount of activated transverse bars could increase, leading to higher punching shear strength. However, the bars located outside the $0.7 d_{0}$ region from the shear-head flange edge should not be accounted in design.

Importantly, the exact amount of activated transverse bars is influenced by the shear flow within the slab which, from a mechanical point of view, is dependent mainly on the strut support and, from a practical point of view, on the shape of the shear-head. For members tested in the current study, the studs located at the composite-to-concrete interface were either activated last (HS13-CT) or provided no contribution (HS13-0T). Therefore, in the design of members with straight-cut shearheads and with shear reinforcement, the transverse bars located at the shear-head tip should not be taken into consideration. However, they must be provided in the flat slab to avoid failures outside of the shear reinforced region. To this end, in the case of ACI-type shear-heads, provided with an inclined cut (e.g. $45^{\circ}$ ), a higher shear could be transferred through that region since it allows the development of a governing strut at the shear-head ends. Consequently, the first transverse bars to be activated (if available) would be those at the interface. On the other hand, a closed shear-head tip could be more constrained in terms of possible force transfer through its tip, and the majority of the shear may be transferred through its sides. In this case, the activated transverse bars would be those located in the vicinity of the flanges.

\section{Concluding Remarks}

This paper focuses on examining the ultimate behaviour of hybrid members consisting of reinforced concrete flat slabs, with and without shear reinforcement, connected to steel columns by fully integrated shear-heads. A detailed account of the results of a series of six large scale tests on hybrid concrete flat slab-to-steel column specimens, of which two were provided with double headed stud rail as shear reinforcement, is presented. The experimental results showed that the behaviour of the hybrid members is directly influenced by the shear-head properties as well as the amount of longitudinal reinforcement and transverse reinforcement (if present). The failure modes were primarily governed by punching shear, even for low conventional reinforcement ratios. Detailed strain measurements illustrated that distinct deformational behaviour typically develop along the orthogonal and diagonal axes of the slab as a function of the in-plane and cross-sectional configuration of the shear-head. The test results indicated that the force transfer between the shearhead assembly and the concrete slab is mobilised through inclined struts supported on the bottom flange of the shear-head. Force transfer through struts, combined with slab rotations, produced inclined shear cracks that initiated at the composite-to-concrete interface. Shear cracks developed below the strut and propagated towards the diagonals of the slab, producing a non-symmetric tridimensional failure surface bounded by an octogonal pattern on the top face of the slab, and a rectangular pattern on the bottom face. For members with shear reinforcement, the critical crack intersected a number of transverse bars, leading to about a twofold increase in the punching shear strength.

The detailed experimental results also provided an in-depth insight of the deformational behaviour of the members, and enabled the development of an axisymmetric hybrid model, and a more simplified bi-linear model, to predict their load-rotation response and flexural strength as a function of the shear-head embedment length, layout and section size. Close examination of the behaviour 
showed that the rotational response of hybrid members is directly influenced by the length and stiffness of the shear-head, which have a direct effect on enhancing the radial moment capacity. However, a change in the cross-section size of the shear-head, within possible practical ranges, has a less significant influence on the rotational and flexural strength of the member in comparison with the amount of longitudinal reinforcement. The main benefit from the presence of the embedded shear-heads is that they shift the critical sections away from the column vicinity, both in terms of bending moment and punching shear, hence significantly delaying failure. The presence of column continuity plates can also enhance the shear-head stiffness and strength, leading to some enhancement of behaviour. Importantly, observed member kinematics indicate a strong dependency between the mobilised failure surface and the shear-head embedment length. Elastic numerical models show nearly symmetric distribution of principal shear forces around the column and shearheads, with high peaks at their tips and lower values along the slab diagonals. In conjunction with experimental observations, this suggests that the critical shear region is a function of the shear-head configuration corresponding to the composite-to-concrete interface, which enables the definition of a shear-head dependent control perimeter required for punching shear assessment.

The axisymmetric and the bi-linear rotational models are employed, in conjunction with the fundamentals of methods established for conventional reinforced concrete slabs, coupled with the definition of a shear-head dependent control perimeter, to carry out a detailed assessment of the punching shear strength of hybrid members with and without shear reinforcement. The detailed and simplified assessment approaches, which employ the proposed rotational models, are shown to be in good agreement with test results reported in this paper as well as those available from previous studies. Analytical design expressions, suitable for practical application, are also proposed and shown to offer equally reliable predictions. Moreover, the adequacy of strength predictions in existing codified design methods, for conventional reinforced concrete members, are examined in the paper. It is shown that these codified approaches either lack specific provisions for members provided with shear-heads or result in over-conservative strength predictions. In contrast, the approaches proposed in this paper provide a more realistic and reliable prediction of the ultimate punching strength of flat slabs, with or without shear reinforcement, and connected to steel columns by means of shear-heads, in comparison with conventional reinforced concrete design provisions.

\section{Acknowledgements}

The financial support of the Research Fund for Coal and Steel of the European Community within the project SMARTCOCO: "Smart Composite Components - Concrete Structures Reinforced by Steel Profiles', Grant No. RFSR-CT-2012-00031, for the tests described in this paper is gratefully acknowledged. The authors would also like to thank the technical staff of the Structures Laboratories at Imperial College London, particularly Mr. T. Stickland and Mr. R. Millward, for their assistance with the experimental work. 


\section{References}

[1] Kahn J, inventor; Trussed Concrete Steel Co, assignee. Floor Construction, US patent 926,497. 1909 June 29

[2] Hardison RM, inventor; Kalman Steel co, assignee. Flat Slab Construction, US Patent 1,550,317. 1925 August 18

[3] Corley WG, Hawkins NM, Shearhead Reinforcement for Slabs. ACI Journal Proceedings 1968;70(11):811-824.

[4] Piel W, Hanswille G, Composite shear head systems for improved punching shear resistance of flat slabs, Composite Construction in Steel and Concrete V, 2006: 226-235.

[5] Tuchschmid AG. Tuchschmid-WALM Dokumentation - Stützenkopfverstärkung - Optimale Krafteinleitung auf tragende Stützen. Frauenfeld (Switzerland): Tuchschmid AG, 2007

[6] Huber K, inventor; Geilinger .AG, assignee. Method of manufacturing a building. Europen patent EP0128994. 1984 December 27

[7] Chana, P. S. and Birjandi, F. K., Design guidance on structural steel shearheads in concrete (shearhead development tests). Report. Department of the Environment, Imperial College London UK; 1996 July, CRIC Report No. CRIC95/001/F

[8] Eder MA, Vollum RL, Elghazouli AY, Inelastic behaviour of tubular column-to-flat slab connections. Journal of Constructional Steel Research, 2011;67(7):1164-1173

[9] Lee CH, Kim JW, Song JG, Punching shear strength and post-punching behaviour of CFT column to RC flat plate connections. Journal of Constructional Steel Research, 2008;64(4):418-428

[10] Kim JW, Lee CH, Kang THK, Shearhead reinforcement for concrete slab to concrete-filled tube column connections. ACI Structural Journal, 2014;111(3):629-638

[11] Eder MA, Vollum RL, Elghazouli AY, Performance of ductile RC flat slab to steel column connections under cyclic loading. Engineering Structures, 2012;36:239-257

[12] Satoh H, Shimazaki K, Experimental research on load eesistance performance of CFT column/flat plate connection. Proceedings of the 13th World Conference on Earthquake Engineering; 2004 August 1-6; Vancouver BC (Canada); 2004. p 976-1

[13] Elstner RC, Hognestad E, Shearing strength of reinforced concrete slabs. ACI Journal, 1956;53(7):29-58

[14] Kinnunen S, Nylander H, Punching of concrete slabs without shear reinforcement. Transactions of the Royal Institute of Technology Stockholm, Sweden, 1960;158(3):1-112

[15] Moe J, Shearing strength of reinforced concrete slabs and footings under concentrated loads. Report. Research and Development Laboratories. Portland Cement Association US; 1961 April, Bulletin D47

[16] ACI 318M-14 building code requirements for structural concrete and commentary. American Concrete Institute; (adopted August 29, 2014; published September 2014)

[17] Bazant ZP, Cao Z, Size effect in punching shear failure of slabs. ACI Structural Journal, 1987;84(1):44-53

[18] Shehata IAEM, Regan PE, Punching in RC Slabs, Journal of Structural Engineering, 1989;115(7):1726-1740 
[19] Hallgren M, Punching shear capacity of reinforced high-strength slabs. Doctorate dissertation. Stockholm, Sweden: KTH Stockholm - TRIT-BKN; 1996

[20] Guandalini S, Burdet O, Muttoni A, Punching tests of slabs with low reinforcement ratios. ACI Structural Journal, 2009;106(1):87-95

[21] Muttoni A, Punching shear strength of reinforced concrete slabs without transverse reinforcement, ACI Structural Journal, 2008;105(4):440-450

[22] fib - Fédération internationale du béton. Model Code 2010 - final draft, vol. 1 \& vol. 2, fib Bulletins 65 \& 66, Lausanne (Switzerland); 2012

[23] Birkle G, Digler WH, Influence of slab thickness on punching shear strength, ACI Structural Journal, 2008;105(2):180-188

[24] Beutel R, Hegger J, The effect of anchorage on the effectiveness of the shear reinforcement in the punching zone. Cement \& Concrete Composites, 2002;24(6):539-549

[25] Gomes RB, Regan PE, Punching resistance of RC flat slabs with shear reinforcement, ASCE Journal of Structural Engineering, 1999;125(6):684-693

[26] Fernández Ruiz M, Muttoni A, Applications of the critical shear crack theory to punching of R/C slabs with transverse reinforcement, ACI Structural Journal, 2009;106(4):485-494.

[27] Lips S, Fernández Ruiz M, Muttoni A, Experimental investigation on punching strength and deformation capacity of shear-reinforced slabs, ACI Structural Journal, 2012;109(6):889-900

[28] EN 1992-1-2 - Eurocode 2: Design of concrete structures - Part 1: General rules and rules for buildings. European Committee for Standardization, Brussels; (December 2004)

[29] Bompa DV, Elghazouli AY, Ultimate shear behaviour of hybrid reinforced concrete beam-to-steel column assemblages. Engineering Structures, 2015;101:318-336

[30] Bompa DV, Oneţ T, Punching shear strength of RC flat slabs at interior connections to columns. Magazine of Concrete Research, In press (published online September 11, 2015) 


\section{Nomenclature}

Greek letters

$\beta_{w}$ - bar inclination

$\delta$ - vertical column displacement

$\varepsilon_{u}-$ ultimate steel strain

$\eta$ - in-plane shear-head layout factor

$\theta_{\text {str }}-$ strut inclination

$\kappa$ - factor

$\lambda_{\psi}-$ hybrid rotation factor

$\lambda$ code - reduction factor

$v_{i}$-shear force per unit width

$\rho_{l}$ - flexural reinforcement ratio

$\rho_{w}$ - shear reinforcement ratio

$\sigma_{s i}-$ stress in reinforcing material

$\psi_{i}-$ slab rotation

$\tau_{\mathrm{bv}}-$ bond stress

Lowercase Latin letters

$b_{0}$ - critical perimeter

$b_{c}-$ column size

$b_{v}$ - shear-head width

$c$-depth of the compression zone

$d$-bending effective depth

$d_{0}$ - shear effective depth

$d g$ - maximum aggregate size

$d_{v i}$ - shear-head component depth

$d_{b w}$ - transverse bar diameter

$f_{c}$ - concrete cylinder strength

$f_{c, \text { cube }}$ - concrete cube strength

$f_{c t, s p}$ - splitting strength

$f_{b d}$-design bond strength

$f_{y s}$ - longitudinal steel strength

$f_{y s w}$ - transverse steel strength

$f_{y v i}$ - shear-head steel strength

$f_{t, i}-$ ultimate steel strength

$h$ - slab thickness

$h_{b w}$ - stud height

$h_{v}$ - shear-head depth

$l_{v}$ - shear-head embedment length

$l, c r-$ radial crack length

$l_{0}$ - critical crack length

$k_{\psi}$ - punching shear factor

$k_{d g}$-size factor

$m_{r, i}-$ radial moment

$m_{t, i}-$ tangential moment

$m_{R, i}-$ plastic moment

$m_{s}-$ design moment

$n_{b w}-$ amount of transverse studs $n_{b w, e f f}-$ activated transverse studs

$r_{i}$ - radius

$r_{c}-$ column radius

$r_{v}-$ hybrid radius

$r_{q}$ - reaction radius

$r_{s}$ - slab radius

$\mathrm{S}_{\mathrm{w}}-$ stud spacing

$w_{\text {cr }}-$ crack width

Uppercase Latin letters

$A_{v}$ - shear head area subjected to slip

$A_{s w}$ - amount of transverse reinforcement

$B$ - span or slab side

$E_{i}$ - elastic modulus

$\mathrm{F}_{\mathrm{i}}$ - internal force

$V_{c r}$ - cracking force

$V_{c}$ - punching shear strength of members

without shear reinforcement or contribution of concrete to punching shear strength of members with shear reinforcement

$V_{f l e x}$ - flexural strength

$V_{i}$ - shear strength/force

$V_{s}$ - shear reinforcement contribution

$V_{\text {test }}$ - test strength

Subscripts

$c$ - concrete

calc-computed

dow-dowel

flex - flexural

in - inside

$k$ - hybrid

max - maximum

out - outside

perp,max - perpendicular maxim

$r$-radial

$s$-steel / reinforcement

$s w$ - transverse reinforcement

$t$ - tangential

test-ultimate test

$v$ - shear-head

$v w$ - shear-head web

$v f t$ - shear-head top flange

$v f b$ - shear-head bottom flange

$x, y$ - orthogonal coordinates 


\section{List of Figures}

Figure 1 a) Schematic representation of the test setup, b) General view of the testing arrangement

Figure 2 Specimen arrangement: a) layout of longitudinal reinforcement, b) cross-sectional view, c) layout of transverse reinforcement, d) cross-sectional view of specimens with transverse reinforcement, e) shearhead details (left: without continuity plate, right: with continuity plate - section details in Table 2

Figure 3 Load versus vertical column displacement for the tested members

Figure 4 Top crack pattern of hybrid members without transverse reinforcement: a) HS13-00, b) HS03-00, c) HS13-C0, d) HS07-C0 (assumed flexural crack pattern is illustrated for HS07-C0).

Figure 5 Cross sectional crack patterns for hybrid members without transverse reinforcement: a) HS13-00 b) HS03-00 c) HS13-C0 d) HS07-C0

Figure 6 Top crack pattern of hybrid members with transverse reinforcement: a) HS13-0T b) HS13-CT

Figure 7 Cross-sectional crack patterns for specimens with transverse reinforcement: a) HS13-0T, b) HS13CT; stud fracture, c) below its head for Specimen HS13-0T, d) near its mid-height for Specimen HS13-CT

Figure 8 Effective stud layout, activated studs, strain gauges location and strain gauge recording on the transverse bars for: a) Specimen HS13-0T, b) Specimen HS13-CT

Figure 9 a) In-plane distribution of the hybrid and RC sectors, b) Cross-sectional view of the model, c) Forces in the hybrid sector, d) Forces in the RC sector, e) Model assumptions

Figure 10 a) Strain profiles and neutral axis in the hybrid sector, b) Strain profiles and neutral axis in the RC sector, c) Surface concrete gauges location, d) Load-strain diagrams of compression surface gauges.

Figure 11 Prediction of the rotational response by the hybrid axisymmetric model and comparison with test results and concrete models for HS03-00.

Figure 12 Qualitative force transfer in the: a) Hybrid sector, b) RC sector

Figure 13 Influence of Shear-head embedment length on the location of the critical section

Figure 14 a) Shear force distribution on the shear-head as recorded by strain gauges, b) Shear flow for Specimen HS13-00

Figure 15 Assumed critical perimeter

Figure 16 Punching shear strength predictions for Specimens: a) HS13-00, b) HS13-C0, c) HS07-C0, d) HS03-00

Figure 17 Assumed critical perimeters for punching shear strength predictions: a) Eurocode 2, b) ACI318, c) Model Code 2010 LoA2, d) Analytical design expressions. (22, 27a).

Figure 18 Statistical illustration of strength predictions: a) Eurocode 2, b) ACI318, c) Model Code 2010 LoA2; d) Detailed assessment approach Eqs. (13, 20, 21), e) Simplified assessment approach Eqs. $(15,20$, 21); f) Analytical design expressions Eqs. (22) (black dots represent tests reported in Section 2 and 3, whereas grey dots represent tests available in the literature)

Figure 19 Strain distribution and neutral axis at failure for specimen HS13-0T

Figure 20 Crack pattern and qualitative force transfer in: a) HS13-CT, b) HS13-0T

Figure 21 Strength predictions for hybrid members with transverse reinforcement: a) HS13-0T b) HS13-CT,

\section{List of Tables}

Table 1. Specimen details and material properties

Table 2. Steel material properties

Table 3. Test results

Table 4. Properties of assessed members without shear reinforcement

Table 5. Prediction results for hybrid members without transverse reinforcement

Table 6. Properties of hybrid members with transverse reinforcement

Table 7. Strength predictions for hybrid members with transverse reinforcement 


\section{Figures}
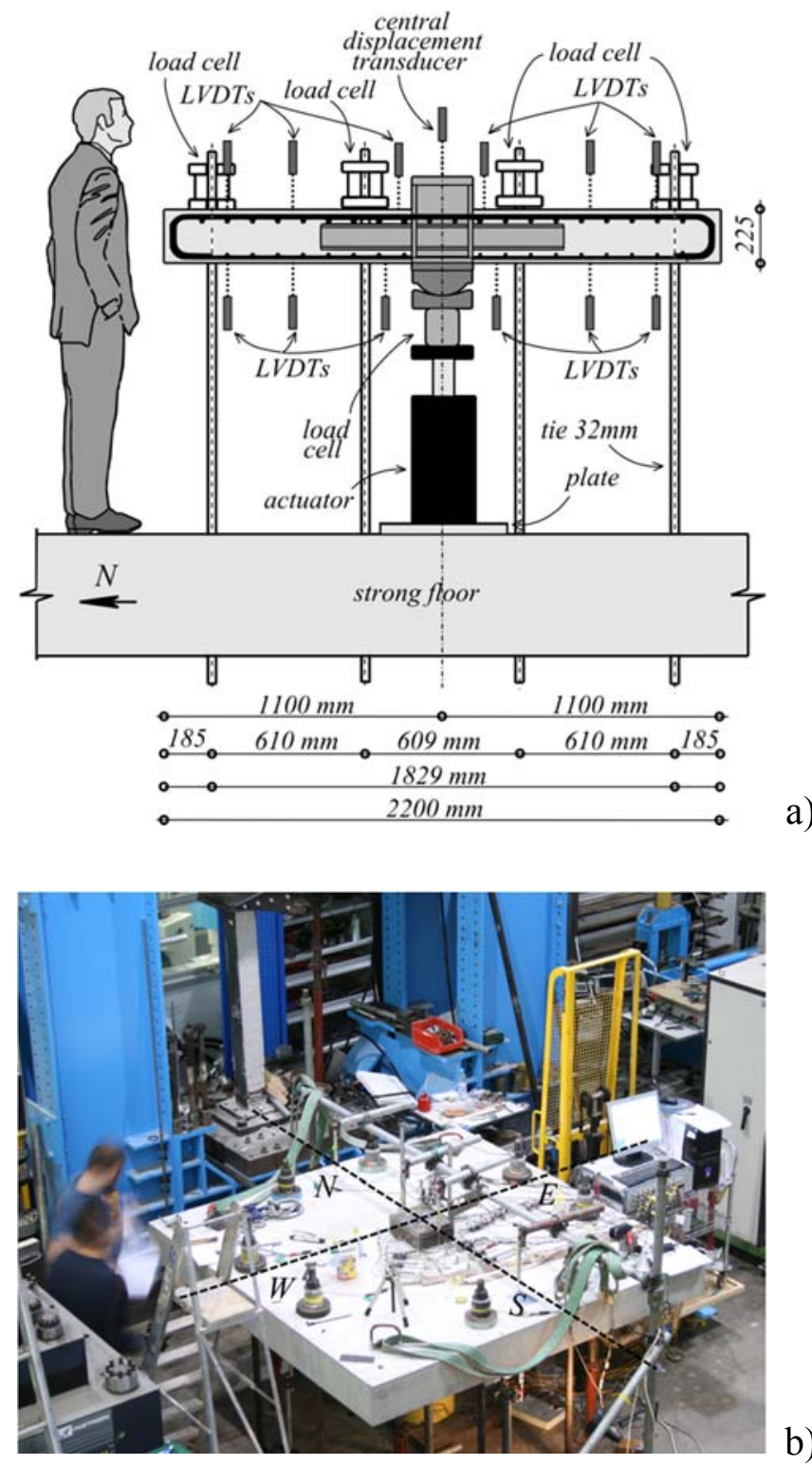

Figure 1 a) Schematic representation of the test setup, b) General view of the testing arrangement 

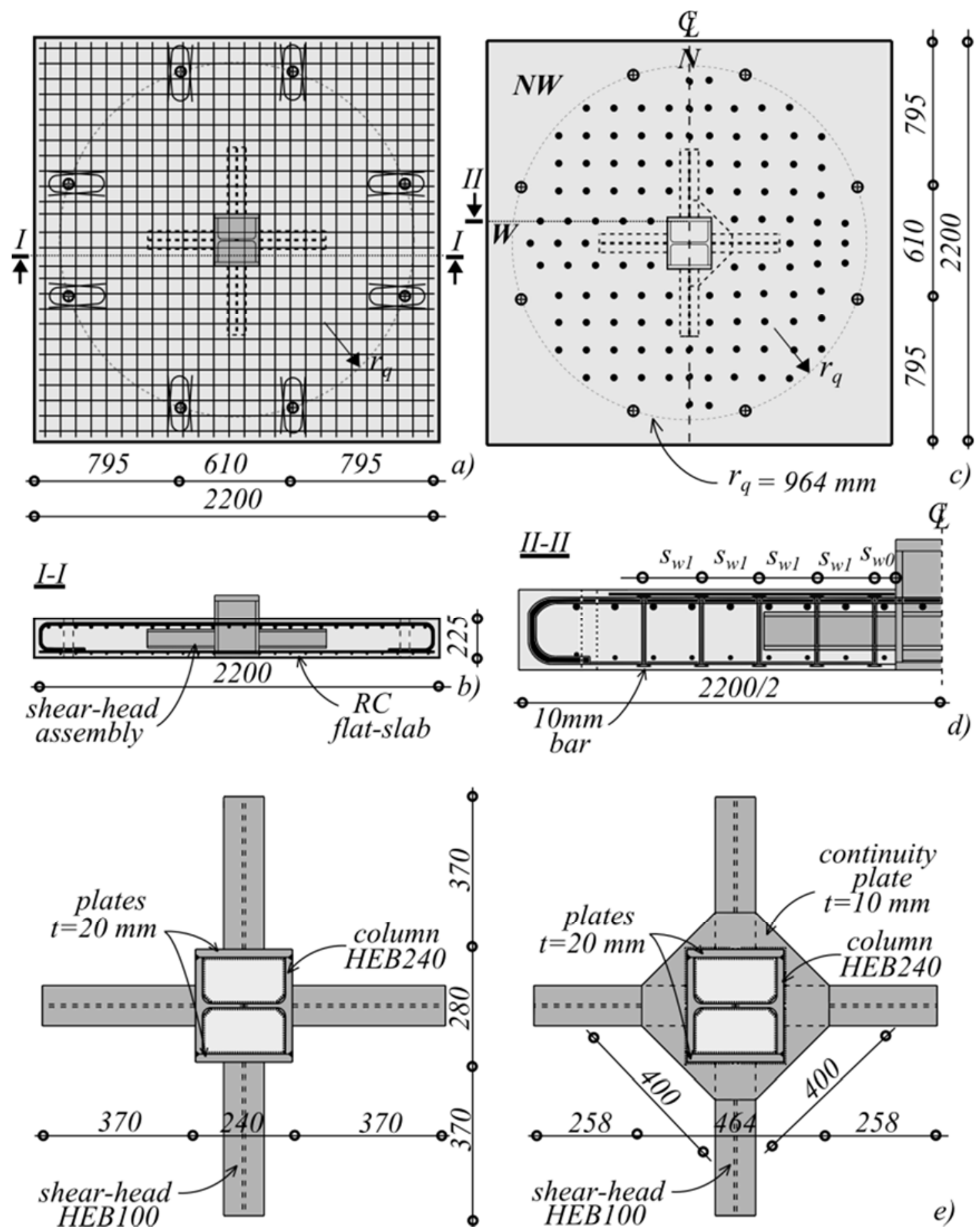

Figure 2 Specimen arrangement: a) layout of longitudinal reinforcement, b) cross-sectional view, c) layout of transverse reinforcement, d) cross-sectional view of specimens with transverse reinforcement, e) shear-head details (left: without continuity plate, right: with continuity plate - section details in Table 2) 


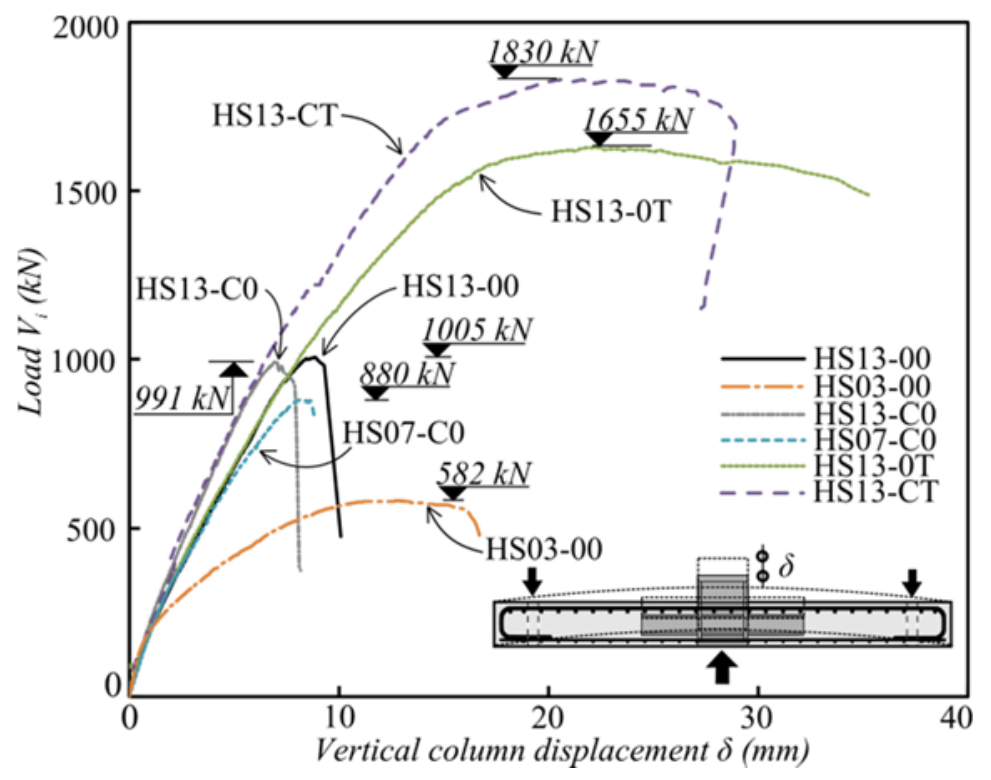

Figure 3 Load versus vertical column displacement for the tested members
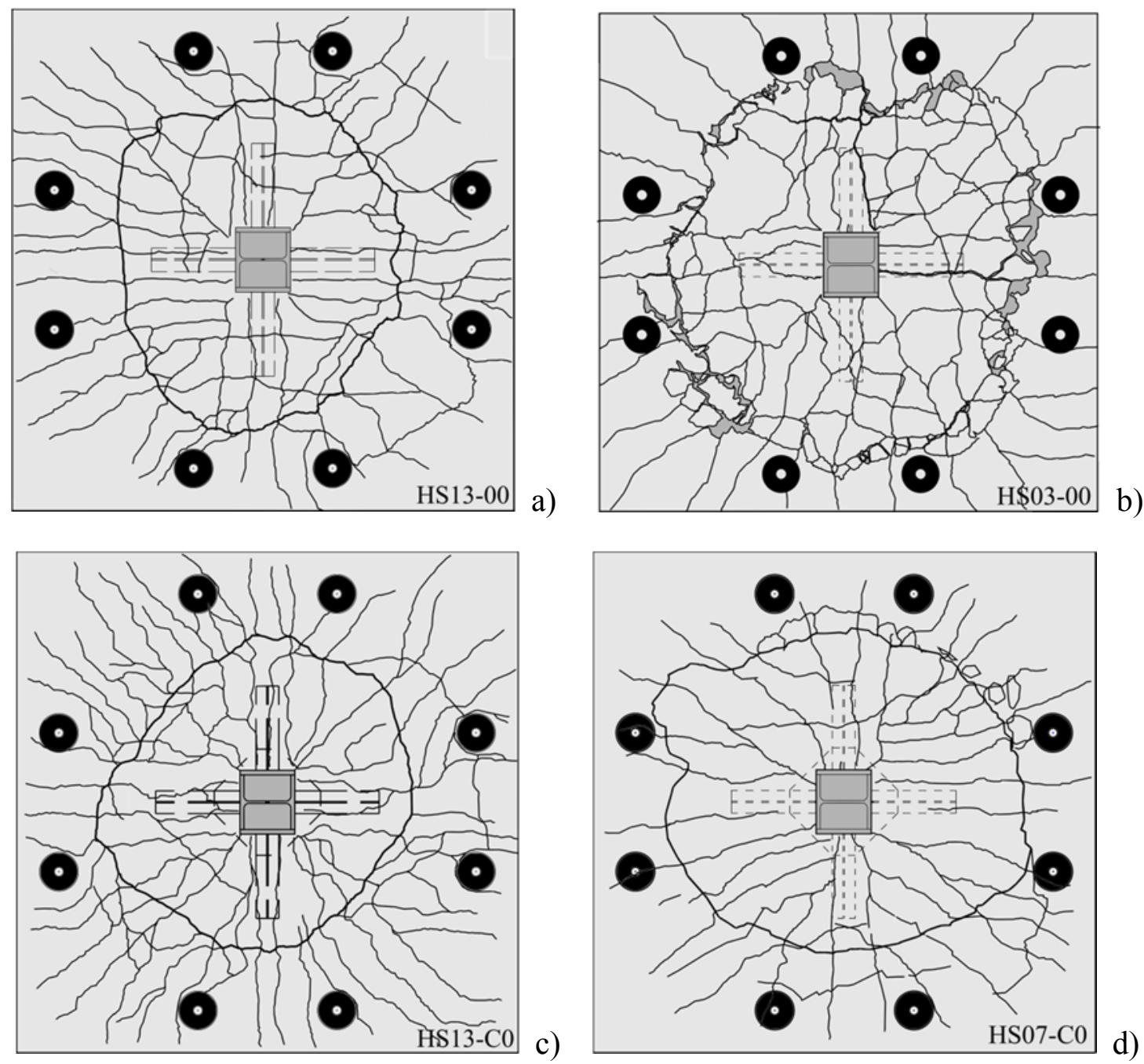

d)

Figure 4 Top crack pattern of hybrid members without transverse reinforcement: a) HS13-00, b) HS03-00, c) HS13-C0, d) HS07-C0 (assumed flexural crack pattern is illustrated for HS07-C0). 


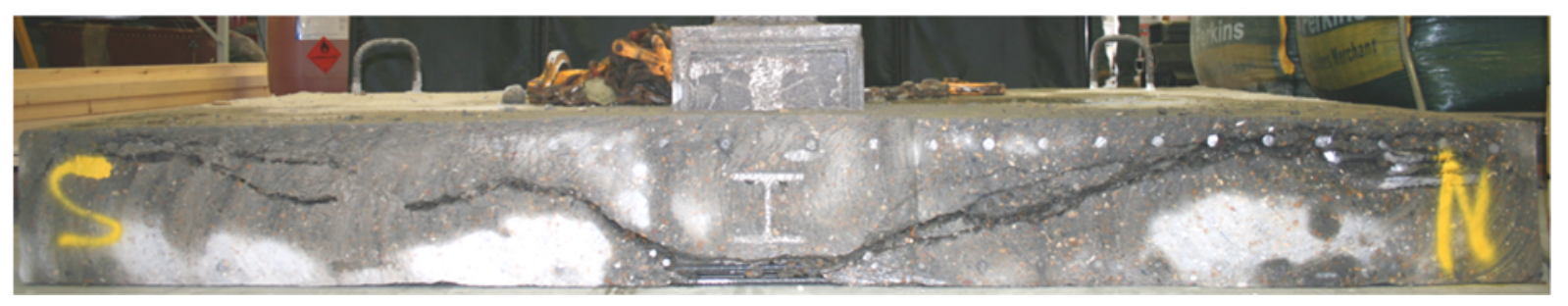

a)

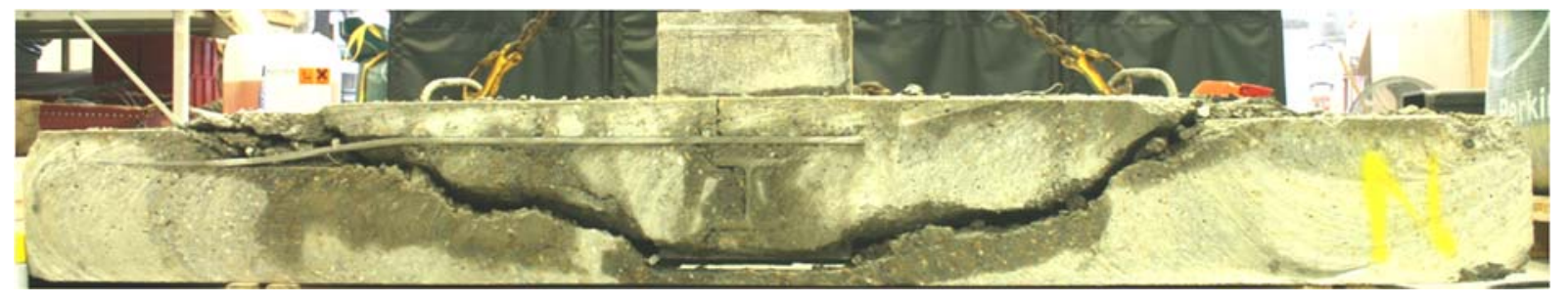

b)

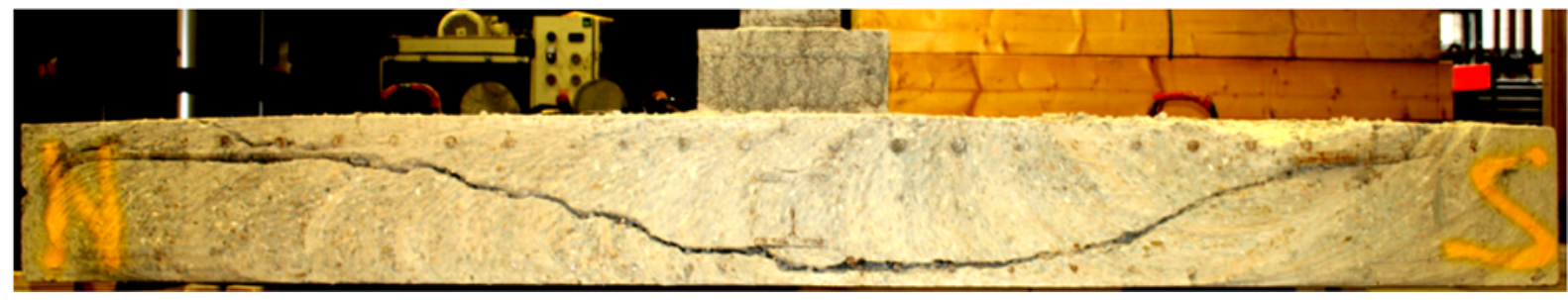

c)

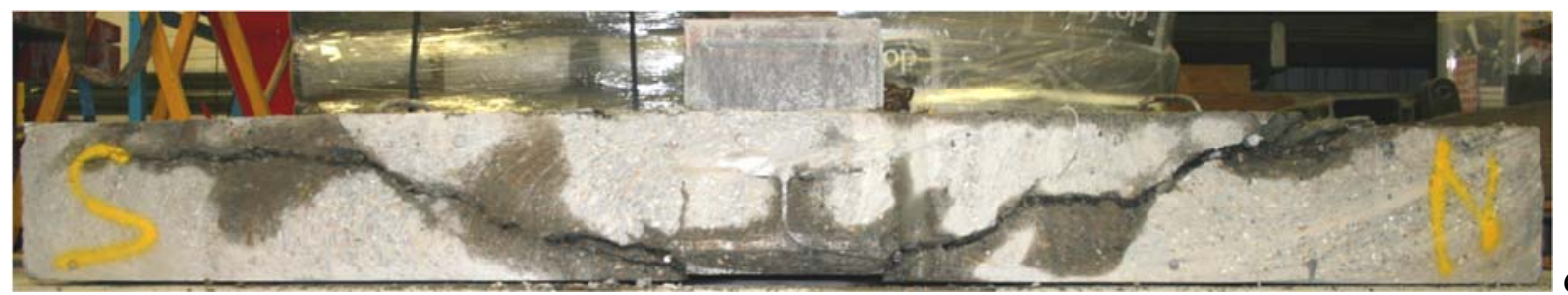

Figure 5 Cross sectional crack patterns for hybrid members without transverse reinforcement: a) HS13-00 b) HS03-00 c) HS13-C0 d) HS07-C0
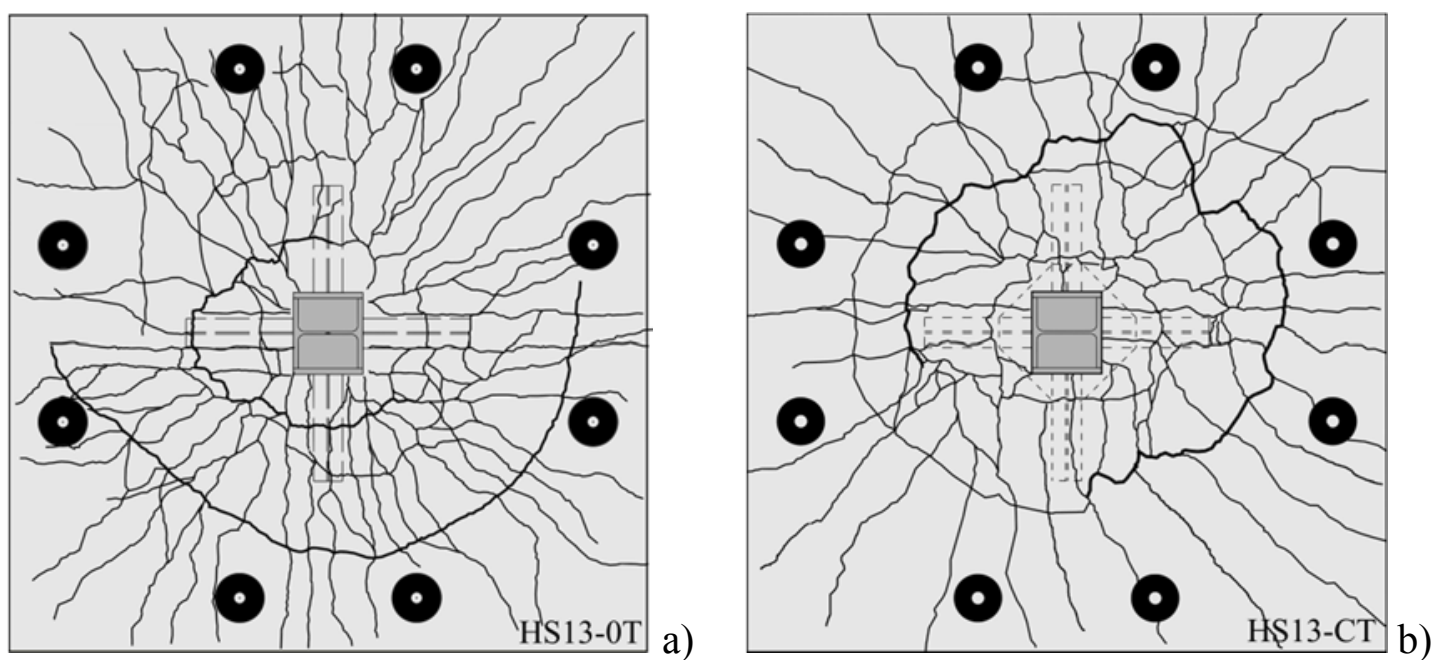

Figure 6 Top crack pattern of hybrid members with transverse reinforcement: a) HS13-0T b) HS13-CT 

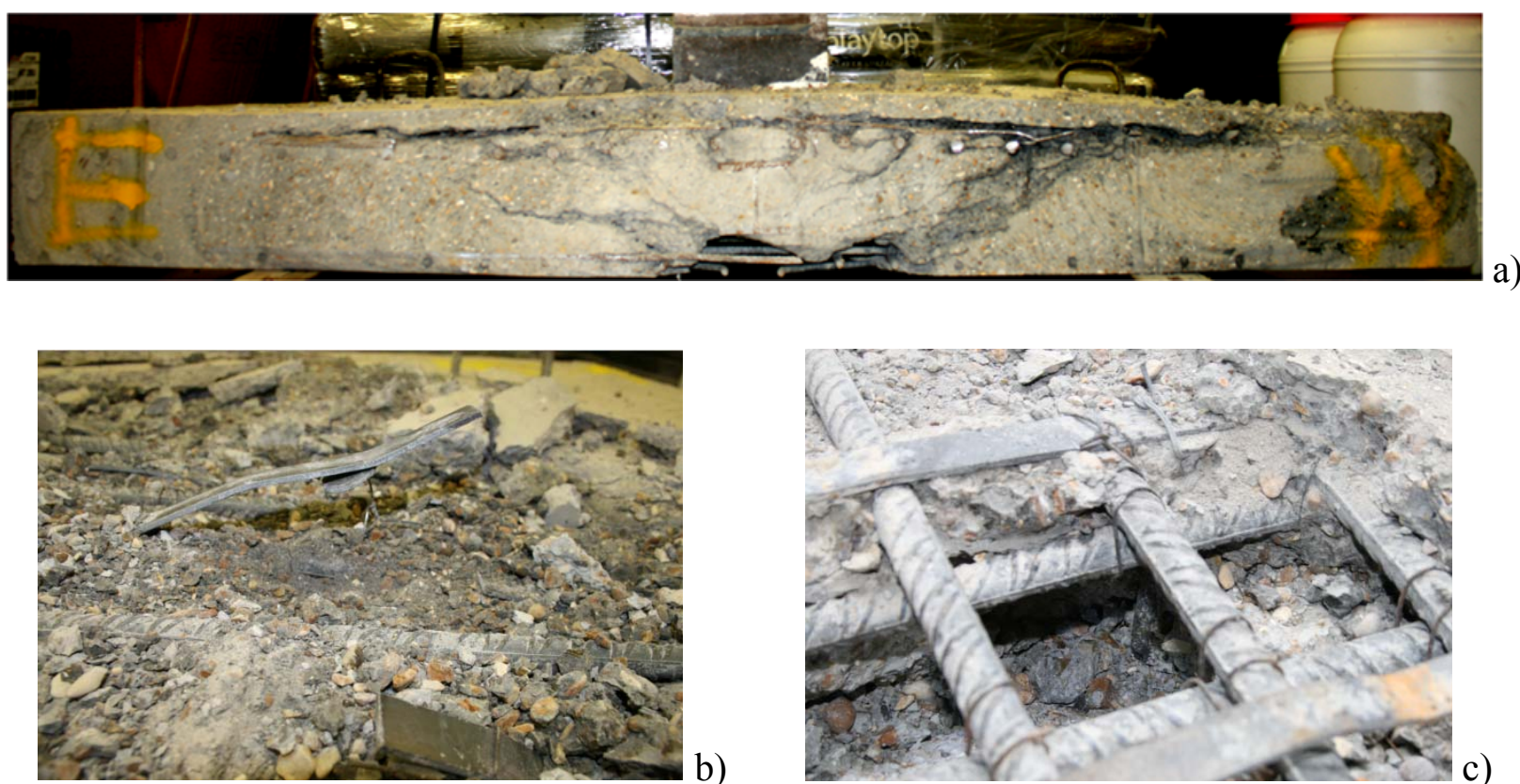

b)
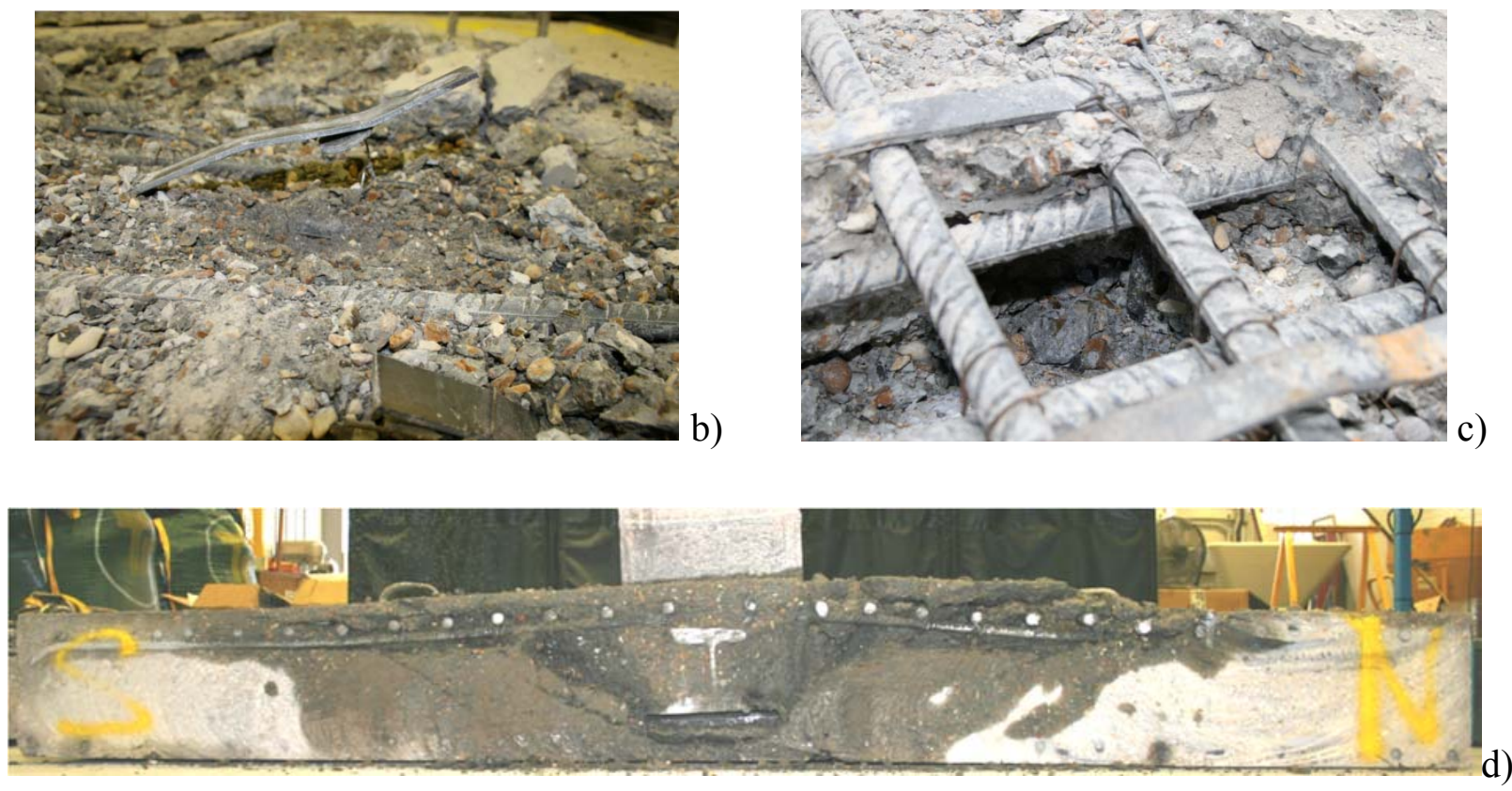

Figure 7 Cross-sectional crack patterns for specimens with transverse reinforcement: a) HS130T, b) HS13-CT; stud fracture, c) below its head for Specimen HS13-0T, d) near its mid-height for Specimen HS13-CT
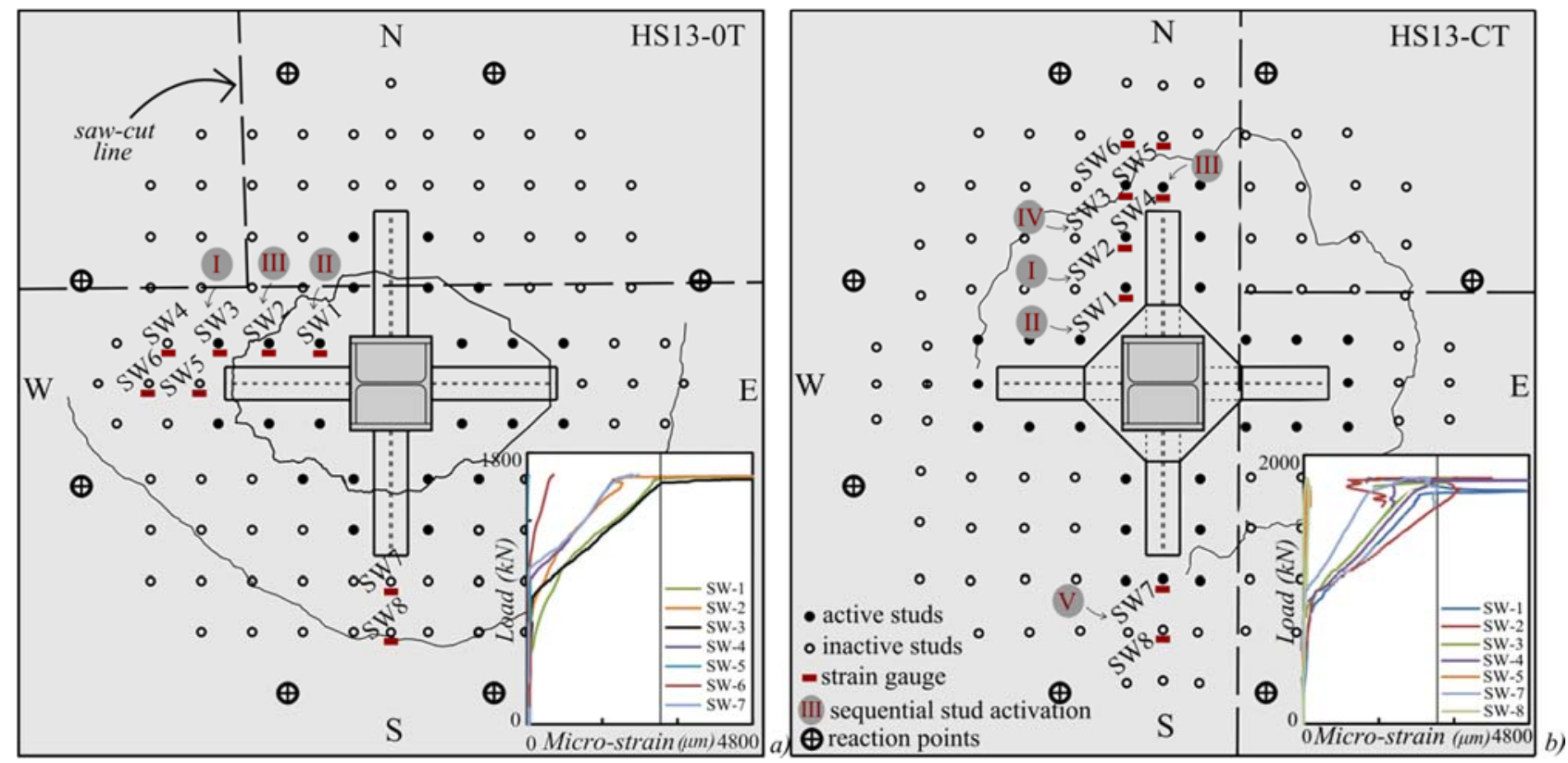

Figure 8 Effective stud layout, activated studs, strain gauges location and strain gauge recording on the transverse bars for: a) Specimen HS13-0T, b) Specimen HS13-CT 

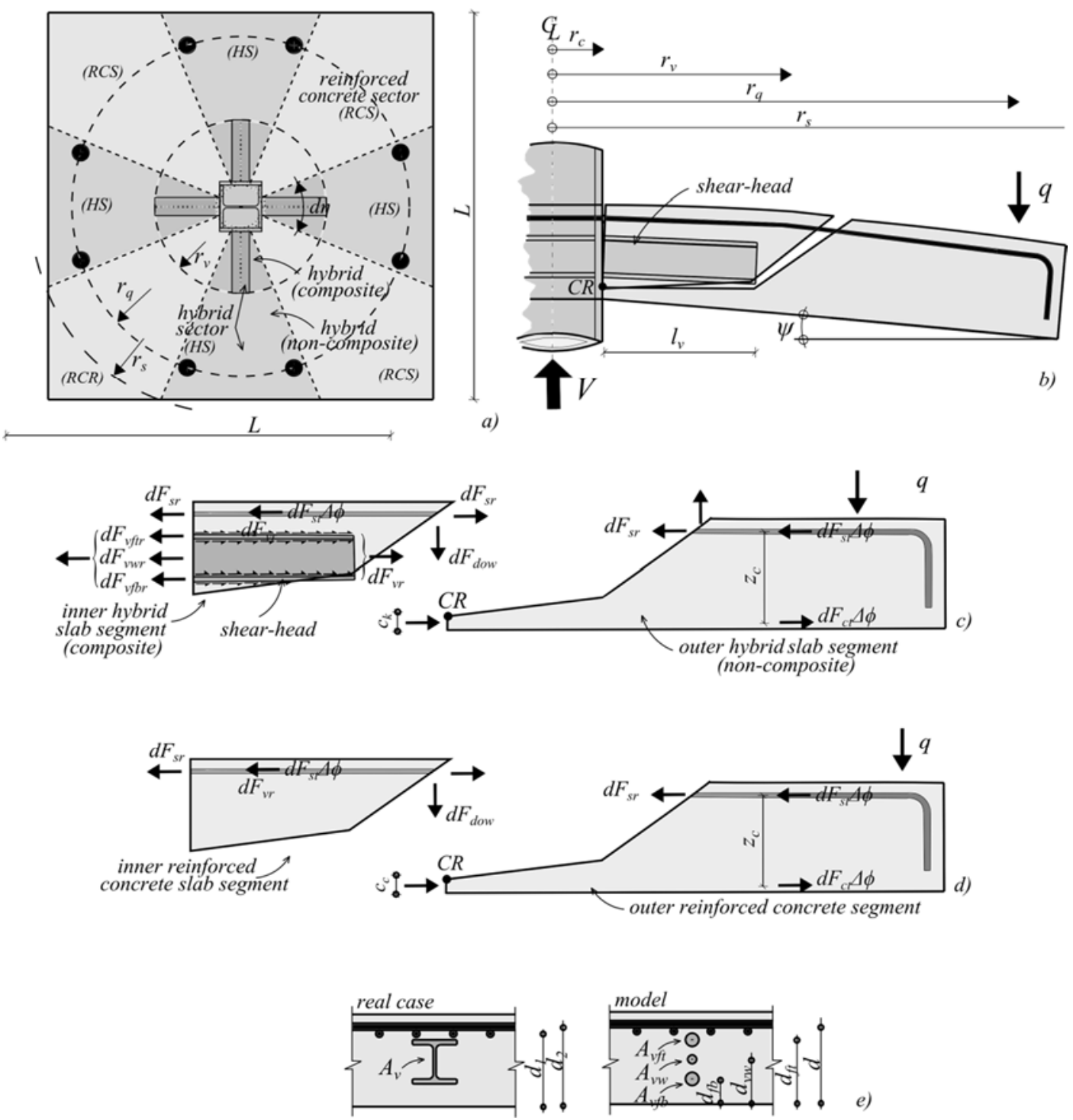

Figure 9 a) In-plane distribution of the hybrid and RC sectors, b) Cross-sectional view of the model, c) Forces in the hybrid sector, d) Forces in the RC sector, e) Model assumptions 

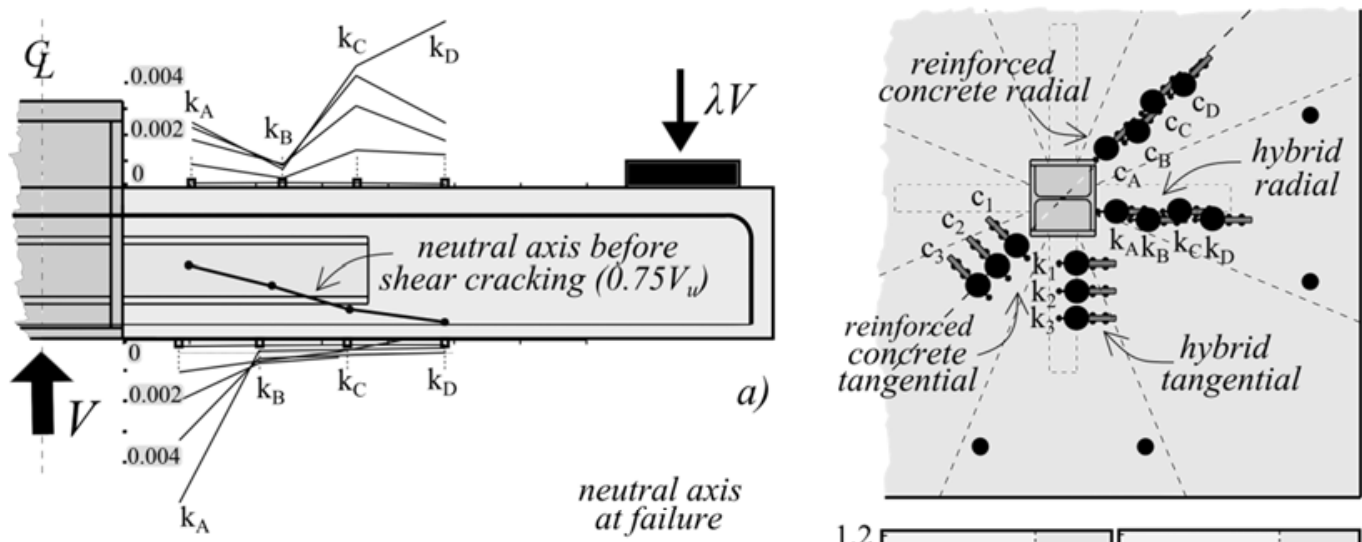

c)
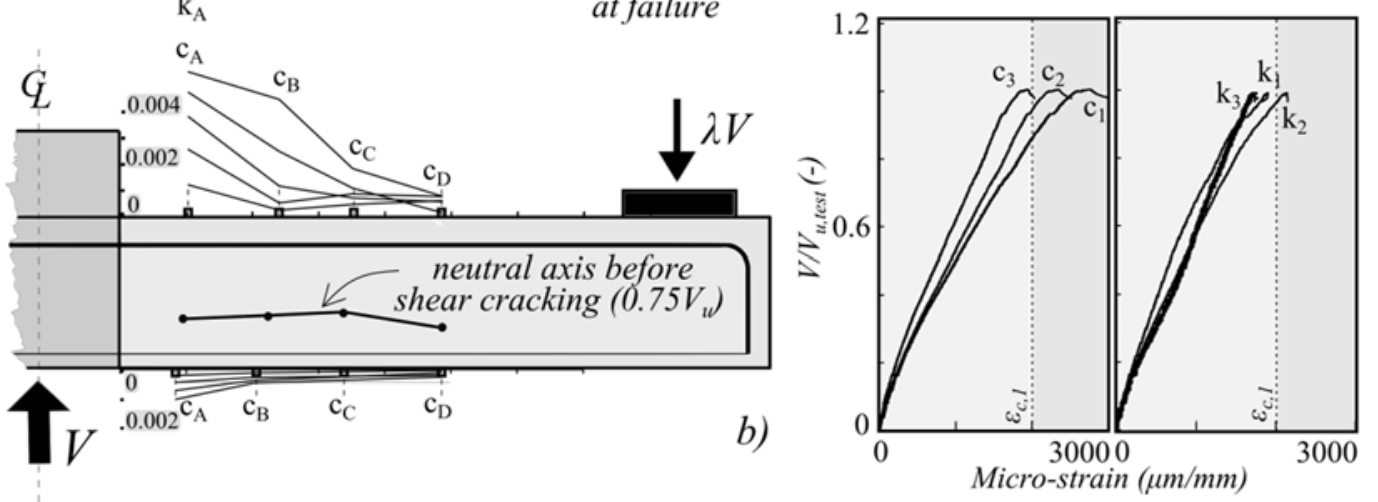

d)

Figure 10 a) Strain profiles and neutral axis in the hybrid sector, b) Strain profiles and neutral axis in the RC sector, c) Surface concrete gauges location, d) Load-strain diagrams of compression surface gauges.

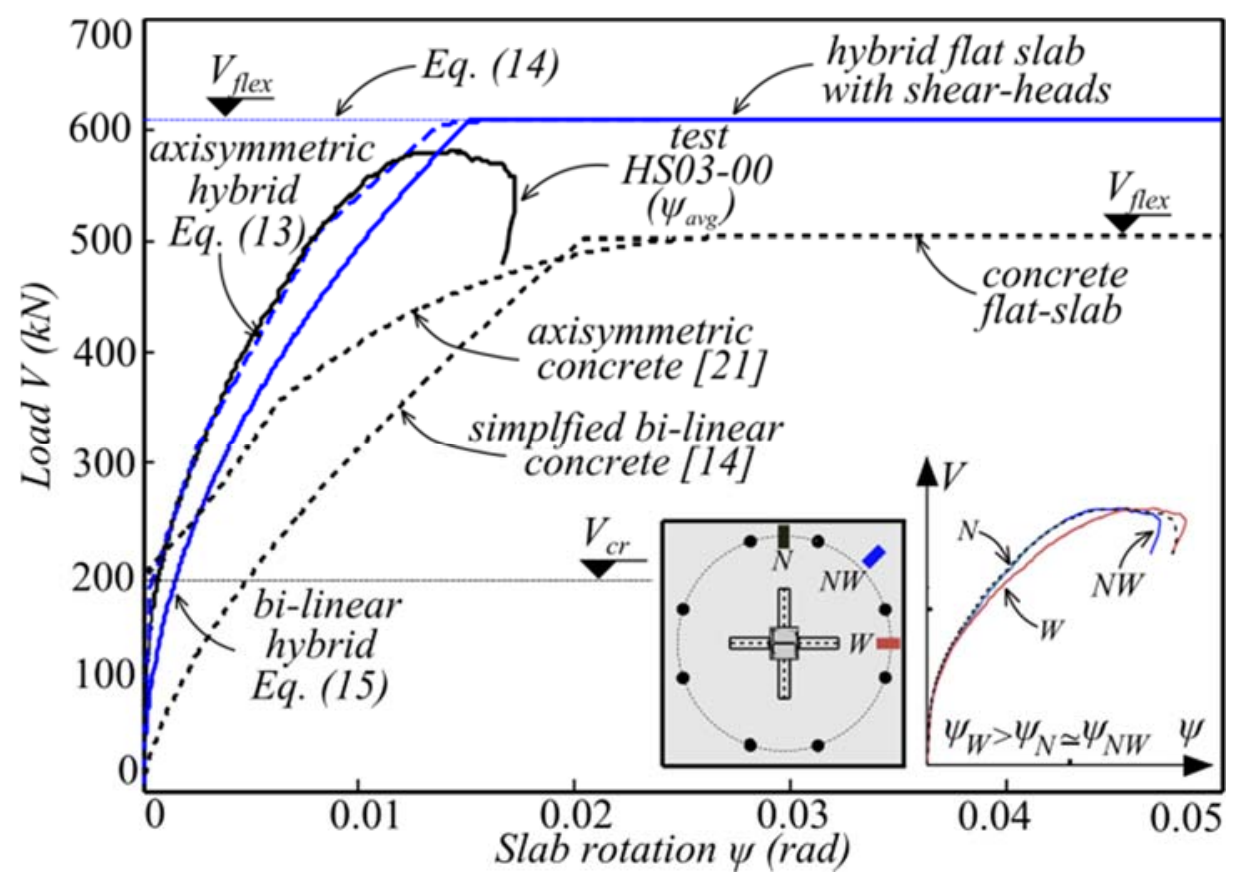

Figure 11 Prediction of the rotational response by the hybrid axisymmetric model and comparison with test results and concrete models for HS03-00. 


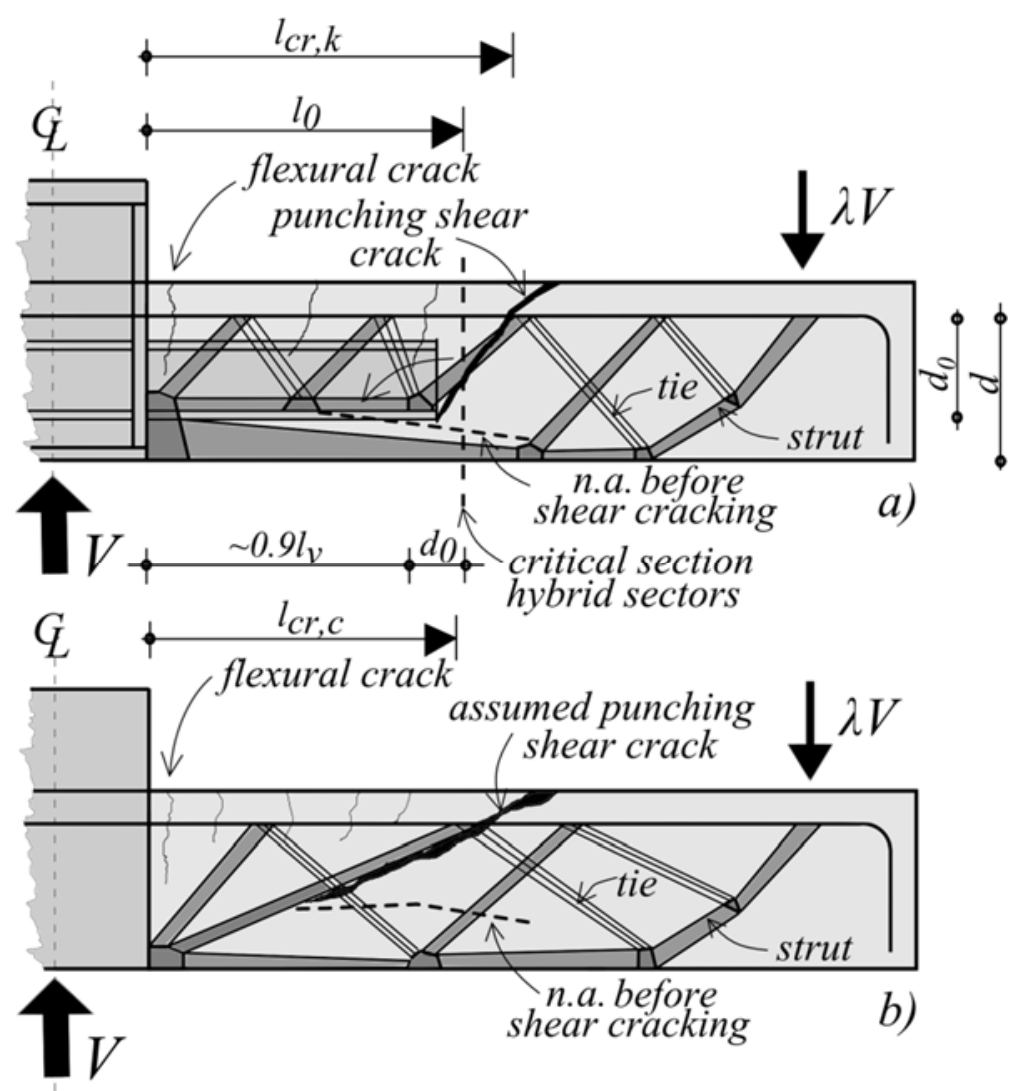

Figure 12 Qualitative force transfer in the: a) Hybrid sector, b) RC sector

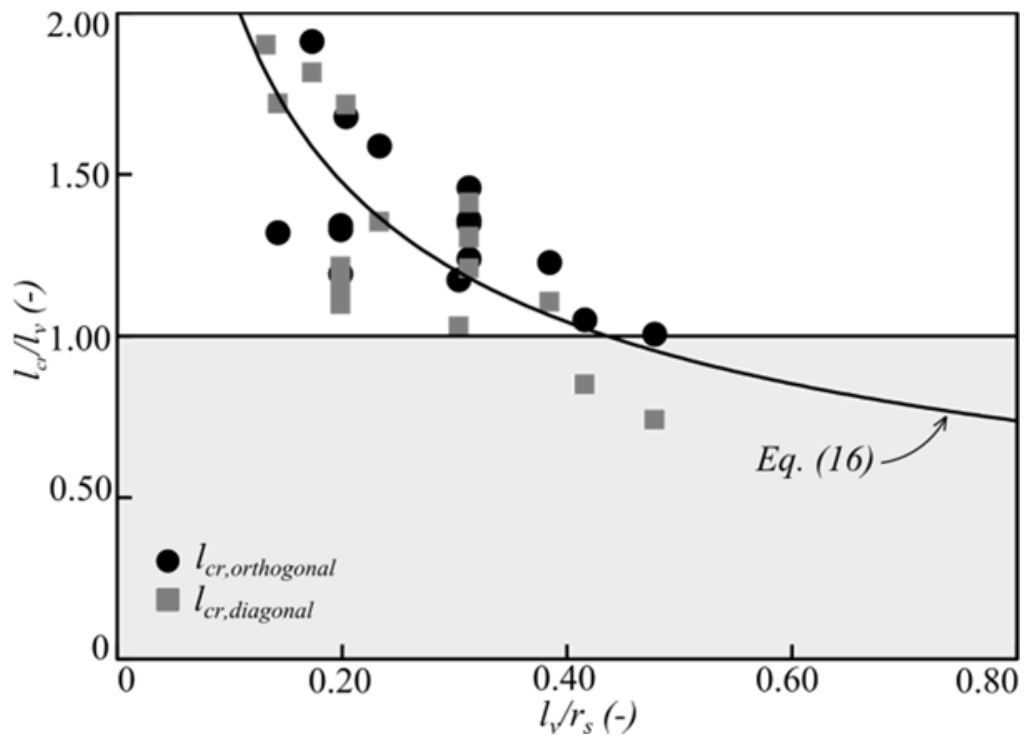

Figure 13 Influence of Shear-head embedment length on the location of the critical section 

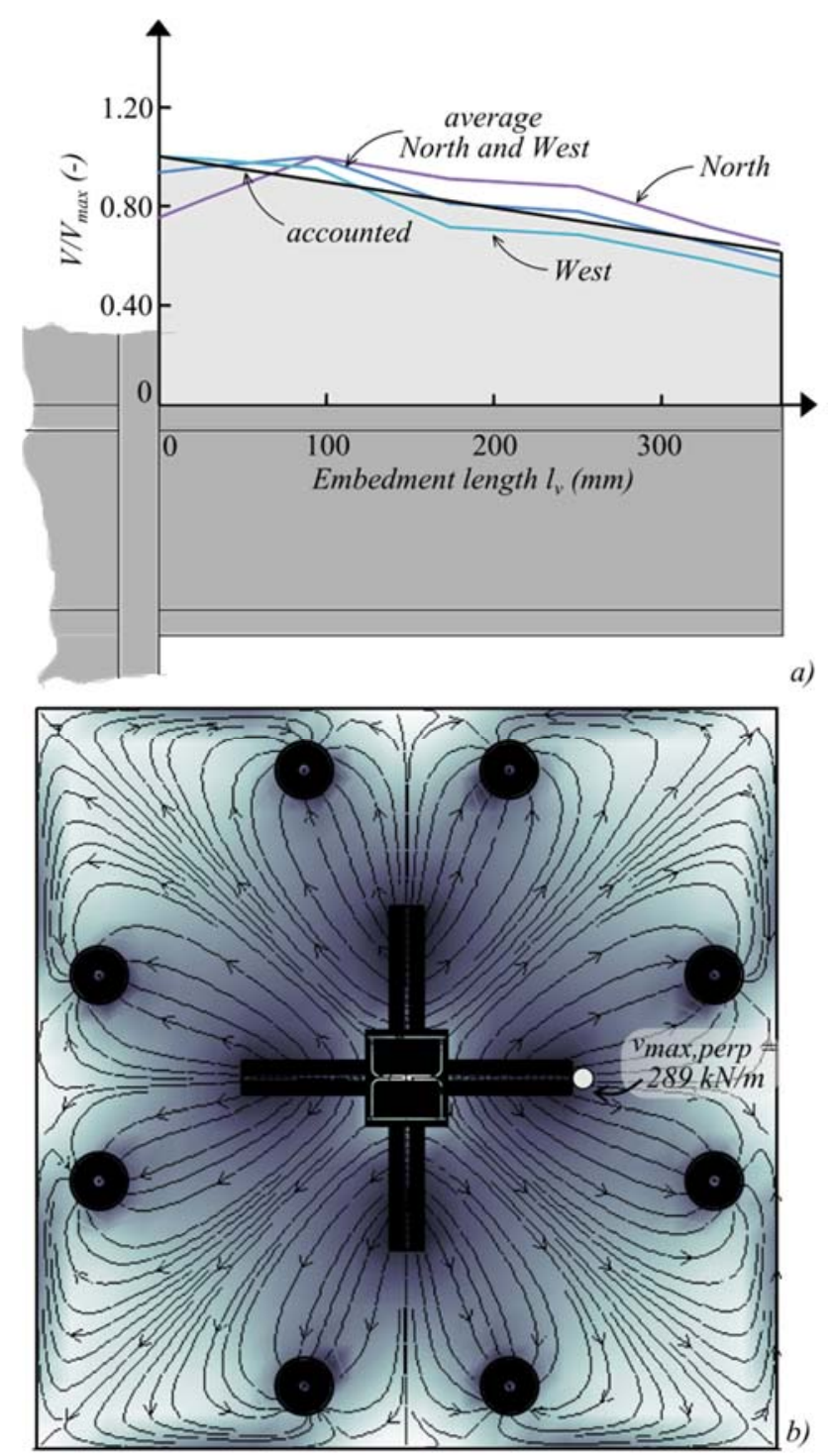

Figure 14 a) Shear force distribution on the shear-head as recorded by strain gauges, b) Shear flow for Specimen HS13-00

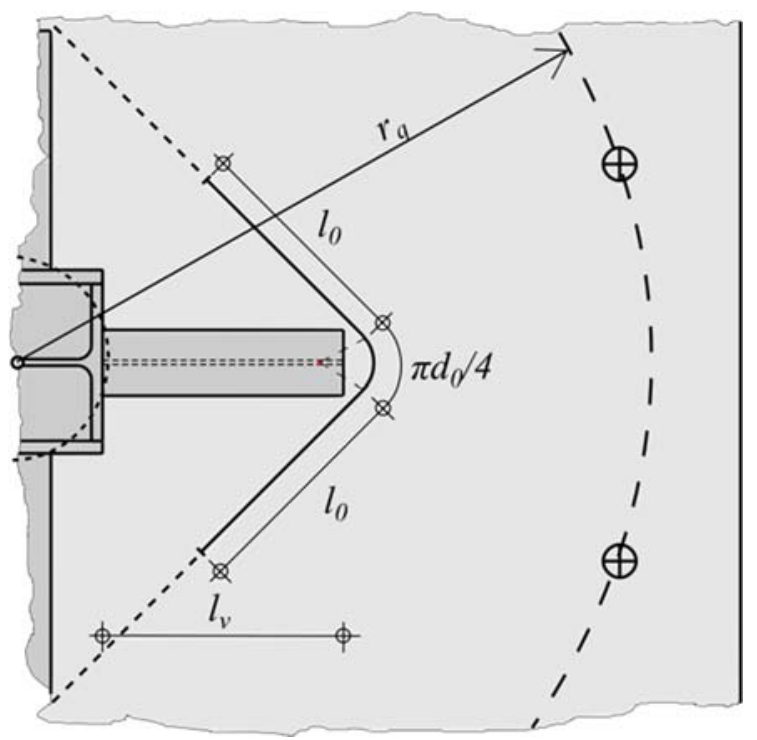

Figure 15 Assumed critical perimeter 41 

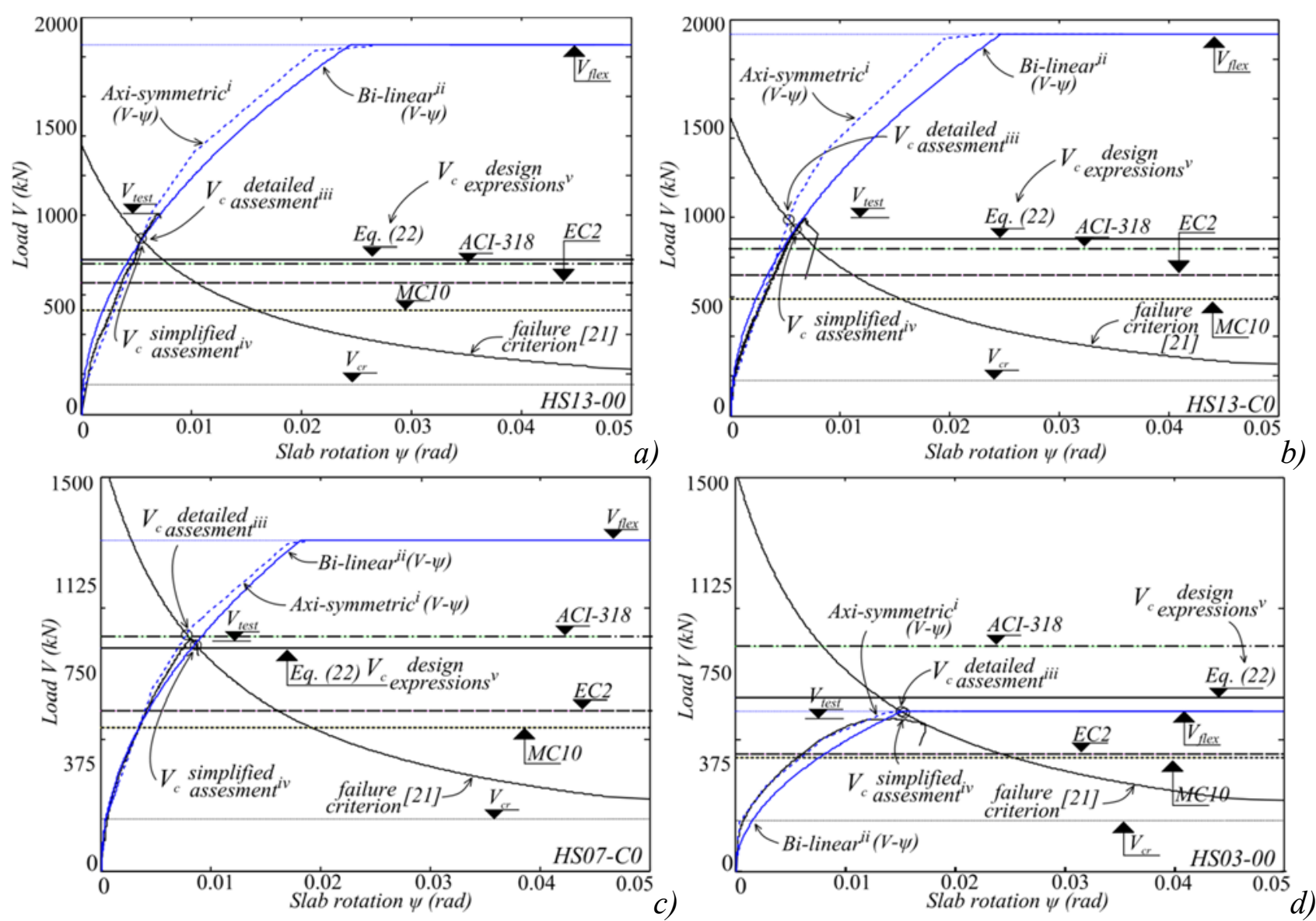

Notes:

i) Axi-symmetric rotational model $V-\psi$ - Eq. (13)

ii) Bi-linear rotational model $V-\psi-$ Eq. (15)

iii)Punching shear strength (simplified assessment approach) Eq. (15, 20, 21)

iv) Punching shear strength (detailed assessment approach) Eq. (13, 20, 21)

v) Punching shear strength (analytical design expressions) Eq. (22)

Figure 16 Punching shear strength predictions for Specimens: a) HS13-00, b) HS13-C0, c) HS07-C0, d) HS03-00 


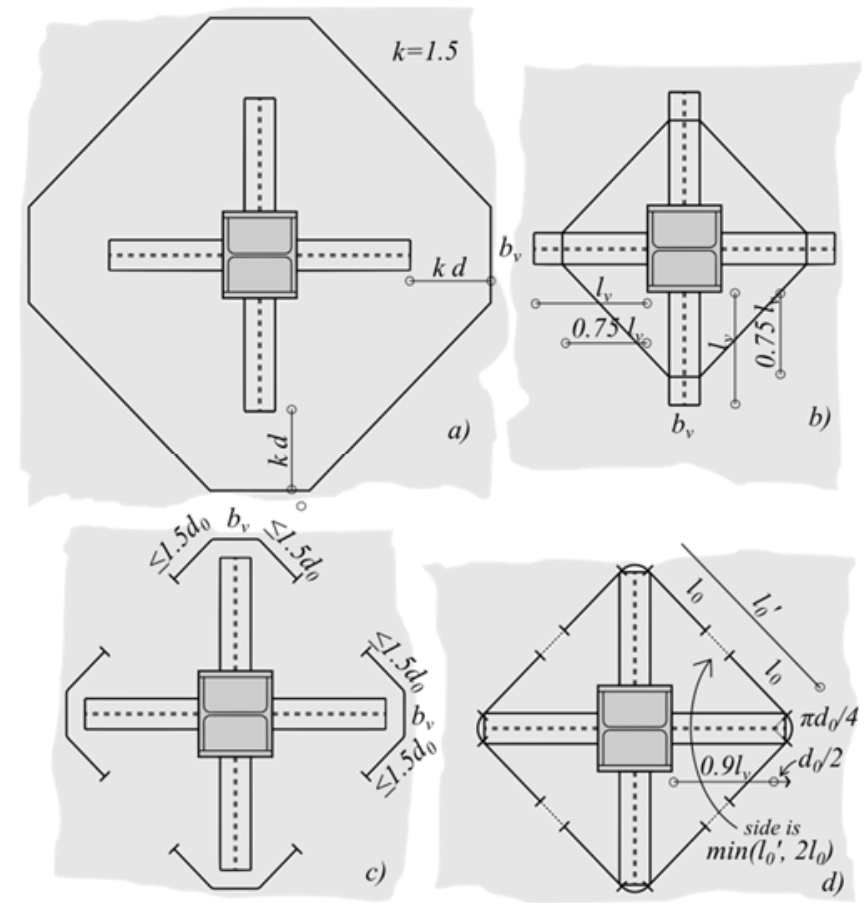

Figure 17 Assumed critical perimeters for punching shear strength predictions: a) Eurocode 2, b) ACI318, c) Model Code 2010 LoA2, d) Analytical design expressions. (22, 27a).
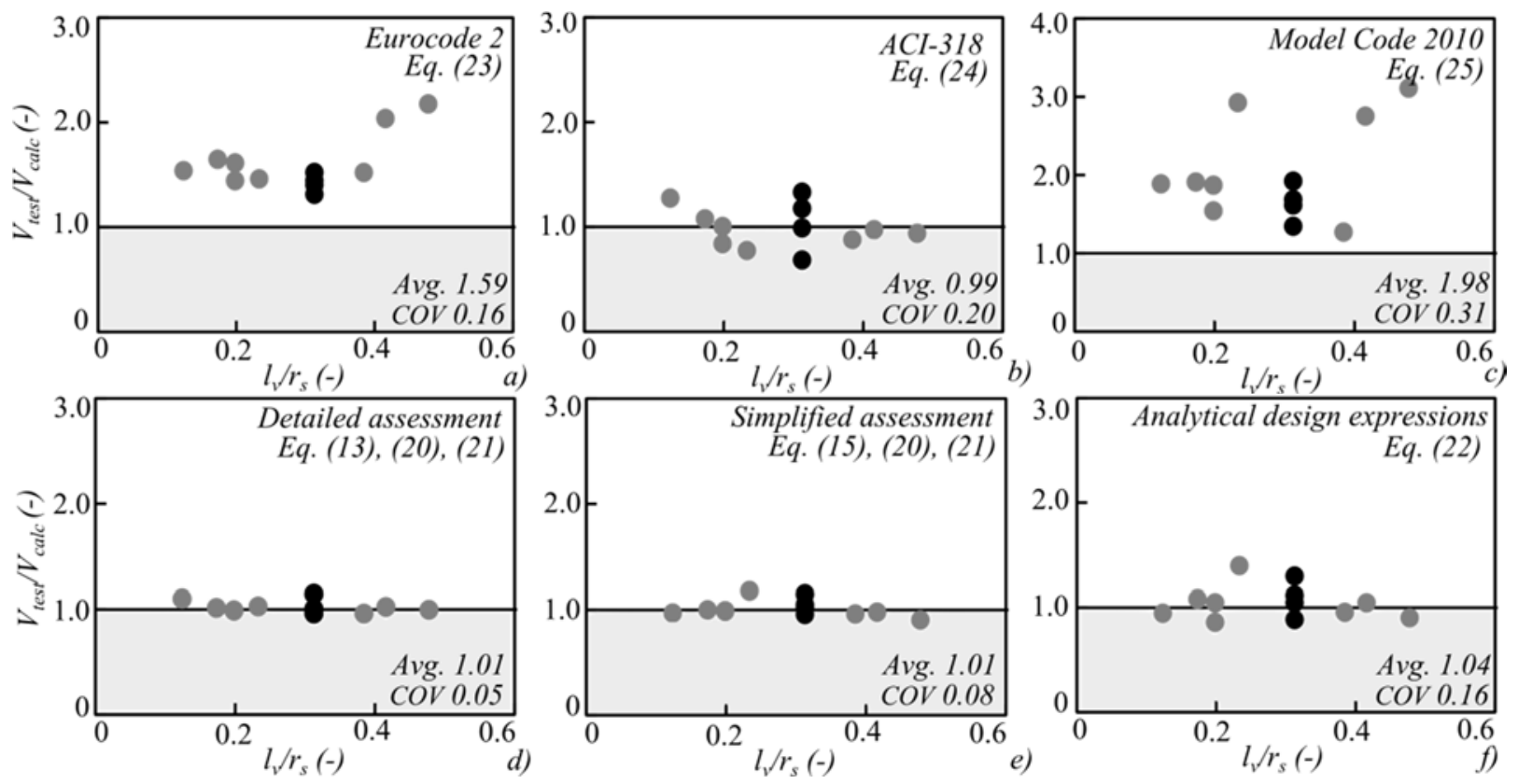

Figure 18 Statistical illustration of strength predictions: a) Eurocode 2, b) ACI318, c) Model Code 2010 LoA2; d) Detailed assessment approach Eqs. (13, 20, 21), e) Simplified assessment approach Eqs. (15, 20, 21); f) Analytical design expressions Eqs. (22) (black dots represent tests reported in Section 2 and 3, whereas grey dots represent tests available in the literature) 


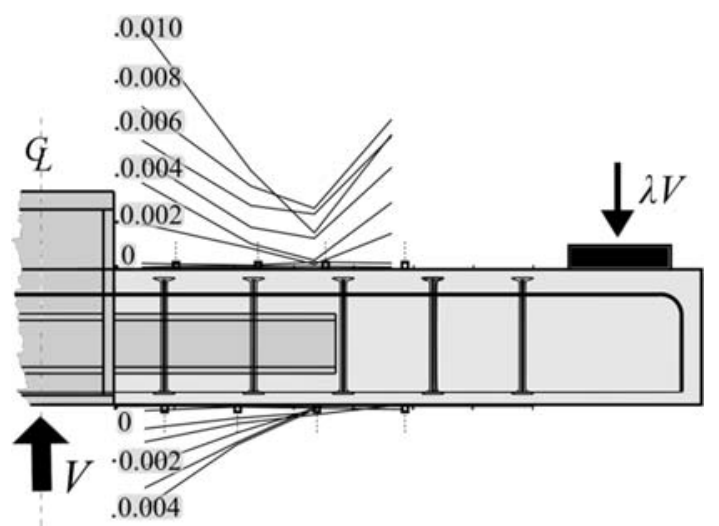

Figure 19 Strain distribution and neutral axis at failure for specimen HS13-0T
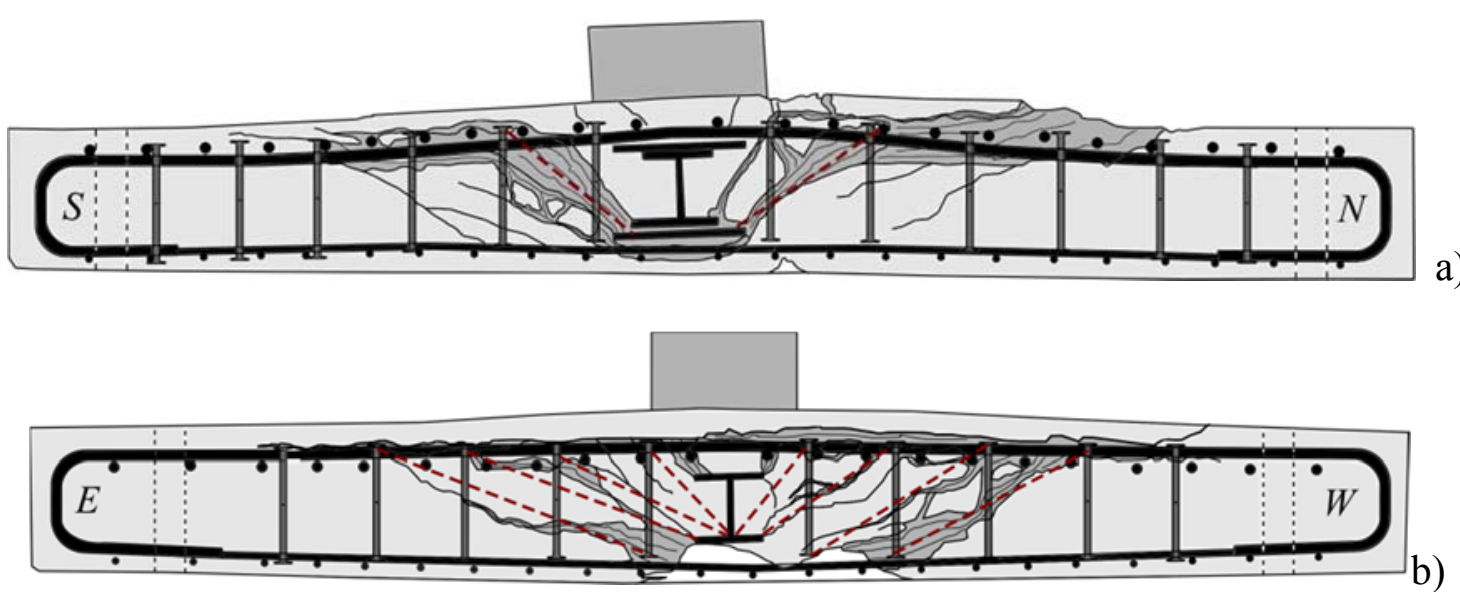

Figure 20 Crack pattern and qualitative force transfer in: a) HS13-CT, b) HS13-0T 

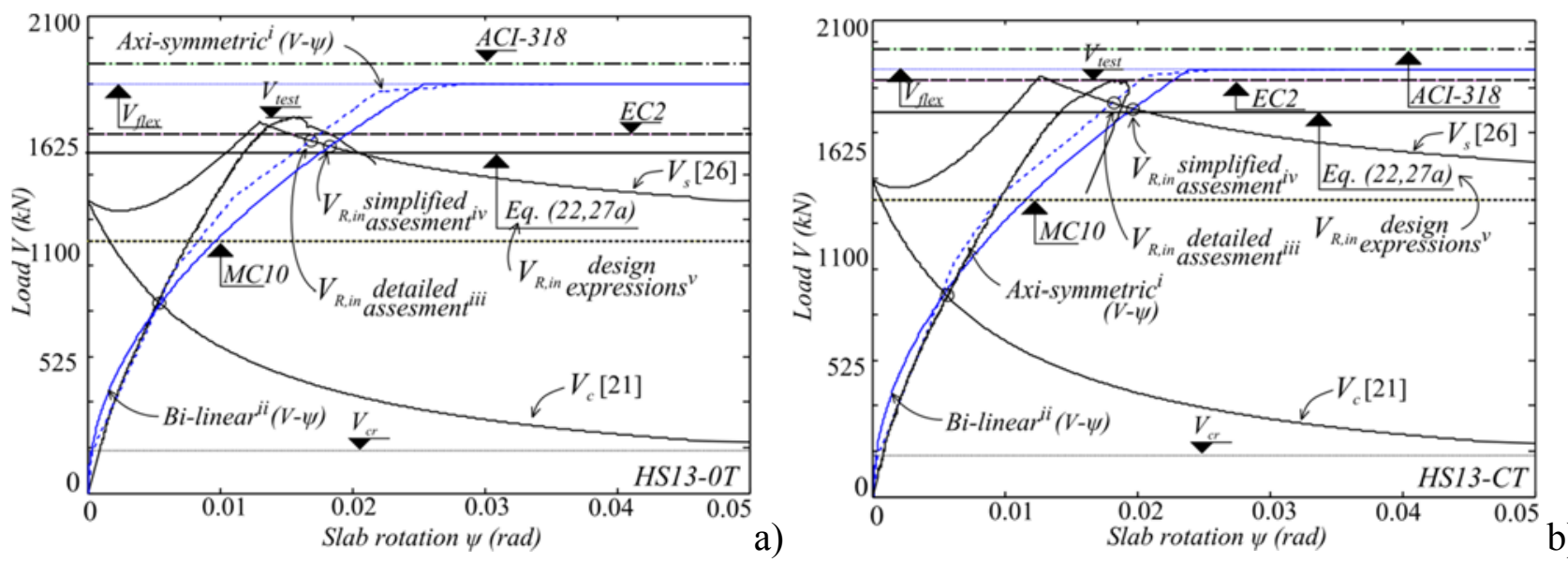

Notes:

i) Axi-symmetric rotational model $V$ - $\psi$ - Eq. (13)

ii) Bi-linear rotational model $V-\psi-$ Eq. (15)

iii) Punching shear strength (simplified assessment approach) Eq. (15, 20, 21)

iv) Punching shear strength (detailed assessment approach) Eq. (13, 20, 21)

v) Punching shear strength (analytical design expressions) Eq. (22)

Figure 21 Strength predictions for hybrid members with transverse reinforcement: a) HS13-0T b) HS13-CT 
Tables

Table 1. Specimen details and material properties

\begin{tabular}{|c|c|c|c|c|c|c|c|c|}
\hline Specimen & $\begin{array}{l}\text { Shear- } \\
\text { head } \\
\text { type }\end{array}$ & $\begin{array}{c}h \\
(\mathrm{~mm})\end{array}$ & $\begin{array}{c}l_{v} \\
(\mathrm{~mm})\end{array}$ & $\begin{array}{c}d \\
(\mathrm{~mm})\end{array}$ & $\begin{array}{l}\rho l \\
(\%)\end{array}$ & $\begin{array}{c}d_{b w} / s_{w} \\
(\mathrm{~mm})\end{array}$ & $\begin{array}{c}f_{c} / f_{c, \text { cube }} \\
/ f_{c t, s p}(M P a)- \\
\text { test day }\end{array}$ & $\begin{array}{c}f_{c} / f_{c, c u b e} \\
\mid f_{c t, s p}(M P a)-28 \\
\text { days }\end{array}$ \\
\hline & HFR100 & & & & & & $29.0 / 32.7 / 2.15$ & $27.4 / 31.3 / 2.24$ \\
\hline & & & & & & & & \\
\hline & & & & & & & & \\
\hline & & & 370 & 11 & & 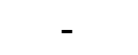 & 2.83 & $34.5 / 42.3 / 3.03$ \\
\hline HS13- & B 100 & 225 & 370 & 172 & & & $7.9 / 31.3 / 2.69$ & $9.2 / 30.9 / 2.88$ \\
\hline HS13-CT & & 225 & 37 & 178 & 1.36 & $0 / 150$ & $.1 / 34.7 / 2.59$ & $30.9 / 2$ \\
\hline
\end{tabular}

$\mathrm{C}-$ continuity plate around the column, $\mathrm{T}-$ presence of transverse reinforcement

Table 2. Steel material properties

\begin{tabular}{llll} 
Sample & $f_{y, 0.2 \%}(\mathrm{MPa})$ & $f_{t, i}(\mathrm{MPa})$ & $\varepsilon_{u}(\%)$ \\
\hline $10 \mathrm{~mm}$ stud (t) & 566 & 660 & 13.1 \\
$10 \mathrm{~mm}$ rebar (1) I & 544 & 626 & 17.4 \\
$16 \mathrm{~mm}$ rebar (1) I & 536 & 636 & 22.4 \\
$10 \mathrm{~mm}$ rebar (l) II & 547 & 634 & 20.0 \\
$16 \mathrm{~mm}$ rebar (l) II & 577 & 692 & 19.8 \\
HEB100 - flange & 457 & 570 & 30.8 \\
HEB100 - web & 461 & 571 & 30.8 \\
HEB240 - flange & 444 & 570 & 31.9 \\
HEB240 - web & 459 & 583 & 30.2 \\
\hline
\end{tabular}

\footnotetext{
Notes

$f_{y 0,2 \%}=0.2 \%$ proof stress, $f_{u}=$ tensile strength and $\varepsilon_{u}=$ the elongation after fracture;

Cross-sectional dimensions:

For HEB 100:

$b \times t_{f} / d \times t_{w} / A_{v} / I_{v}=100 \mathrm{~mm} \times 10 \mathrm{~mm} / 100 \mathrm{~mm} \times 6 \mathrm{~mm} / 2600 \mathrm{~mm}^{2} / 449.5 \times 10^{4} \mathrm{~mm}^{4}$

For HEB 240:

$b \times t_{f} / d \times t_{w} / A_{v} / I_{v}=240 \mathrm{~mm} \times 17 \mathrm{~mm} / 240 \mathrm{~mm} \times 10 \mathrm{~mm} / 106 \times 10^{2} \mathrm{~mm}^{2} / 11260 \times 10^{4} \mathrm{~mm}^{4}$
}

Table 3. Test results

\begin{tabular}{cccccccccc} 
& Spec. & type & $\begin{array}{c}h \\
(\mathrm{~mm})\end{array}$ & $\begin{array}{c}d \\
(\mathrm{~mm})\end{array}$ & $\begin{array}{c}f_{c} \\
(\mathrm{MPa})\end{array}$ & $\begin{array}{c}\rho_{l} \\
(\%)\end{array}$ & $\begin{array}{c}d_{b} / \mathrm{S}_{w l} \\
(\mathrm{~mm})\end{array}$ & $\begin{array}{c}V_{\text {test }} \\
(\mathrm{kN})\end{array}$ & $\begin{array}{c}\delta_{\text {Vtest }} \\
(\mathrm{mm})\end{array}$ \\
\hline 1 & HS13-00 & HEB100 & 226 & 177 & 29 & 1.37 & - & 1005 & 8.80 \\
6 & HS03-00 & HEB100 & 225 & 175 & 37.5 & 0.33 & - & 582 & 13.0 \\
\hline 2 & HS13-C0 & HEB100 & 225 & 175 & 36.5 & 1.33 & - & 991 & 7.00 \\
5 & HS07-C0 & HEB100 & 225 & 178 & 39.2 & 0.75 & - & 880 & 8.15 \\
\hline 3 & HS13-0T & HEB100 & 225 & 172 & 27.9 & 1.35 & $10 / 150$ & 1655 & 21.7 \\
4 & HS13-CT & HEB100 & 225 & 178 & 29.1 & 1.36 & $10 / 150$ & 1830 & 21.6 \\
\hline
\end{tabular}

$\mathrm{C}-$ continuity plate around the column, $\mathrm{T}-$ presence of transverse reinforcement 
Table 4. Properties of assessed members without shear reinforcement

\begin{tabular}{|c|c|c|c|c|c|c|c|c|c|c|c|c|c|}
\hline 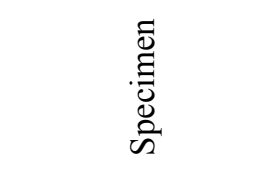 & 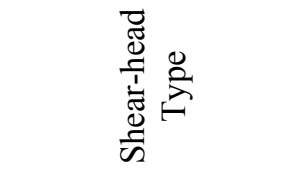 & 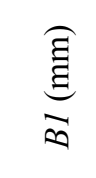 & 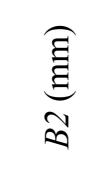 & $\underbrace{\Xi \Xi}_{=}$ & $\underbrace{\Xi}_{0}$ & 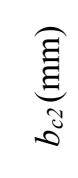 & $\underbrace{\Xi \Xi \Xi}_{\Xi}$ & $\underbrace{\stackrel{\Xi \Xi}{\Xi}}_{\circlearrowright}$ & $\underbrace{a}_{\frac{a}{a}}$ & 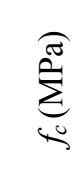 & 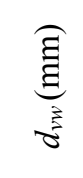 & 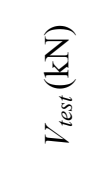 & $\frac{\sqrt[3]{5}}{A^{3}} I$ \\
\hline HS13-00 [\#] & HEB100 & 200 & 2200 & 370 & 240 & 280 & 225 & 177 & 1.38 & 29.0 & 102 & 1005 & 0.54 \\
\hline HS13-C0 [\#] & HEB100 & 200 & 2200 & 370 & 240 & 280 & 225 & 175 & 1.39 & 36.5 & 102 & 991 & .52 \\
\hline $\mathrm{HS} 07-\mathrm{C} 0[\#]$ & HEB100 & 2200 & 2200 & 370 & 240 & 280 & 225 & 178 & 0.75 & 39.2 & 102 & 880 & 0.70 \\
\hline $\mathrm{HS} 03-\mathrm{C} 0[\#]$ & HEB100 & 2200 & 2200 & 370 & 240 & 280 & 225 & 175 & 0.33 & 37.5 & 102 & 582 & 0.95 \\
\hline Type A [8] & $2 \times \mathrm{RSC} 51 \times 38 \times 6$ & 3270 & 2900 & 410 & 180 & 180 & 155 & 123 & 0.92 & 37.9 & 77.5 & 450 & 0.72 \\
\hline SH490 S200 [10] & $\mathrm{H} 100 \times 100 \times 6 \times 8$ & 3000 & 3000 & 490 & 400 & 400 & 200 & 164 & 0.68 & 22.8 & 80 & 754 & 1.10 \\
\hline SH770 C500 [10] & $2 \times \mathrm{H} 100 \times 100 \times 6 \times 8$ & 3000 & 3000 & 770 & 500 & 500 & 200 & 161 & 1.47 & 22.8 & 80 & 1135 & 0.85 \\
\hline SH320WT19 [10] & $\mathrm{H} 100 \times 100 \times$ & 3000 & 3000 & 320 & 400 & 400 & 200 & 164 & 0.68 & 22.8 & 80 & 674 & 0.99 \\
\hline SH670WT19 [10] & $2 \times \mathrm{H} 100 \times 100 \times 6 \times 8$ & 3000 & 3000 & 670 & 400 & 400 & 200 & 161 & 1.26 & 22.8 & 80 & 1007 & 0.88 \\
\hline SH620300 [10] & $\mathrm{H} 150 \times 150 \times 7 \times 10$ & 3000 & 3000 & 620 & 400 & 400 & 300 & 264 & 0.54 & 22.8 & 105 & 1434 & 0.96 \\
\hline FPPSH [9] & $\mathrm{H} 100 \times 100 \times 6 \times 8$ & 3000 & 3000 & 320 & 400 & 400 & 200 & 164 & 0.68 & 17.1 & 80 & 627 & 0.99 \\
\hline SH320PR [10] & $\mathrm{H} 100 \times 100 \times 6 \times 8$ & 3000 & 3000 & 320 & 400 & 400 & 200 & 164 & 0.68 & 34.6 & 83 & 694 & 0.98 \\
\hline FPPST [9] & $\mathrm{T}-89 \times 50 \times 9 \times 9$ & 3000 & 3000 & 200 & 400 & 400 & 200 & 164 & 0.68 & 18.1 & 55 & 597 & 0.96 \\
\hline
\end{tabular}

[\#] this paper; $d_{g}=10 \mathrm{~mm}$ for members reported in this paper and [8], and $d_{g}$ is assumed $16 \mathrm{~mm}$ for [9],[10]

Table 5. Prediction results for hybrid members without transverse reinforcement

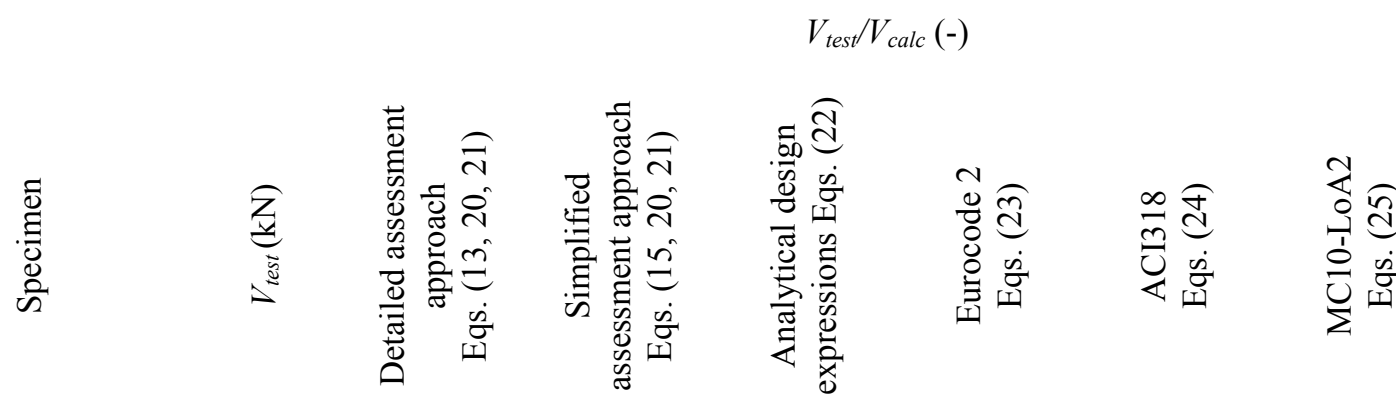

\begin{tabular}{cccccccc}
\hline HS13-00 [\#] & 1005 & 1.14 & 1.14 & 1.29 & 1.52 & 1.33 & 1.92 \\
HS13-C0 [\#] & 991 & 1.00 & 1.04 & 1.11 & 1.40 & 1.17 & 1.68 \\
HS07-C0 [\#] & 880 & 0.98 & 1.02 & 1.04 & 1.44 & 0.99 & 1.61 \\
HS03-C0 [\#] & 582 & 0.96 & 0.95 & 0.88 & 1.31 & 0.68 & 1.34 \\
Type A [8] & 450 & 1.03 & 1.17 & 1.39 & 1.45 & 0.77 & 2.92 \\
SH70 C500 [10] & 1135 & 0.99 & 0.90 & 0.90 & 2.17 & 0.93 & 3.10 \\
SH320 WT19[10] & 674 & 0.99 & 0.99 & 1.04 & 1.61 & 1.00 & 1.86 \\
SH670 WT19[10] & 1007 & 1.02 & 0.97 & 1.04 & 2.03 & 0.97 & 2.75 \\
SH620 300 [10] & 1434 & 0.96 & 0.96 & 0.95 & 1.52 & 0.88 & 1.27 \\
FPP SH [9] & 627 & 1.01 & 0.99 & 1.08 & 1.64 & 1.08 & 1.91 \\
SH320 PR [10] & 694 & 0.98 & 0.98 & 0.86 & 1.44 & 0.84 & 1.54 \\
FPP ST [9] & 597 & 1.09 & 0.96 & 0.94 & 1.53 & 1.27 & 1.88 \\
\hline Average & & 1.01 & 1.01 & 1.04 & 1.59 & 0.99 & 1.98 \\
COV & & 0.05 & 0.08 & 0.16 & 0.16 & 0.20 & 0.31
\end{tabular}

[\#] this paper 
Table 6 Properties of hybrid members with transverse reinforcement

\begin{tabular}{ccccccccccccc} 
Specimen & Type & $\begin{array}{c}B 1 \\
(\mathrm{~mm})\end{array}$ & $\begin{array}{c}B 2 \\
(\mathrm{~mm})\end{array}$ & $\begin{array}{c}l_{v} \\
(\mathrm{~mm})\end{array}$ & $\begin{array}{c}c_{1} \\
(\mathrm{~mm})\end{array}$ & $\begin{array}{c}c_{2} \\
(\mathrm{~mm})\end{array}$ & $\begin{array}{c}h \\
(\mathrm{~mm})\end{array}$ & $d(\mathrm{~mm})$ & $\begin{array}{c}\rho_{l} \\
(\%)\end{array}$ & $\begin{array}{c}f_{c} \\
(\mathrm{MPa})\end{array}$ & $\begin{array}{c}d_{g} \\
(\mathrm{~mm})\end{array}$ & $\begin{array}{c}d_{v w} \\
(\mathrm{~mm})\end{array}$ \\
\hline HS13-0T & HEB100 & 2200 & 2200 & 370 & 240 & 280 & 225 & 172 & 1.41 & 27.9 & 10 & 102 \\
HS13-CT & HEB100 & 2200 & 2200 & 370 & 240 & 280 & 225 & 178 & 1.36 & 29.1 & 10 & 102 \\
\hline \multirow{2}{*}{ Specimen } & Type & $\begin{array}{c}d_{b w} \\
(\mathrm{~mm})\end{array}$ & $\begin{array}{c}n_{b w} \\
(-)\end{array}$ & $\begin{array}{c}n_{b w, e f f} \\
(-)\end{array}$ & $\begin{array}{c}S_{w, 0} \\
(\mathrm{~mm})\end{array}$ & $\begin{array}{c}S_{w, 1} \\
(\mathrm{~mm})\end{array}$ & $\begin{array}{c}h_{b w} \\
(\mathrm{~mm})\end{array}$ & $\begin{array}{c}f_{\text {ysw }} \\
(\mathrm{MPa})\end{array}$ & $\begin{array}{c}f_{\text {tsw }} \\
(\mathrm{MPa})\end{array}$ & $\begin{array}{c}d_{0} \\
(\mathrm{~mm})\end{array}$ & $\begin{array}{c}V_{\text {test }} \\
(\mathrm{kN})\end{array}$ & $\begin{array}{c}V_{f l e x} \\
(\mathrm{kN})\end{array}$ \\
\hline HS13-0T & DHSR* & 10 & 108 & 24 & 70 & 150 & 190 & 566 & 660 & 110 & 1655 & 1792 \\
HS13-CT & DHSR* & 10 & 112 & 28 & 70 & 150 & 190 & 556 & 660 & 116 & 1830 & 1880 \\
\hline
\end{tabular}

*DHSR - double headed stud rail shear reinforcement

Table 7 Strength predictions for hybrid members with transverse reinforcement

$$
V_{\text {test }} / V_{\text {calc }}(-)
$$

\begin{tabular}{|c|c|c|c|c|c|c|c|}
\hline 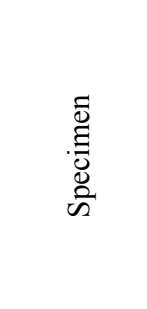 & 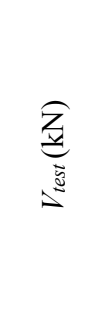 & 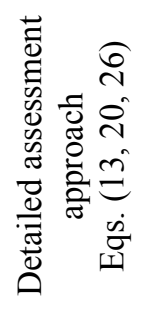 & 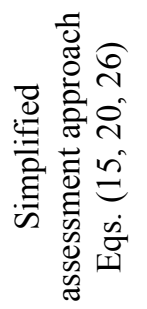 & 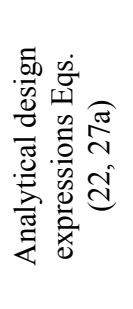 & 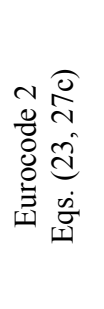 & 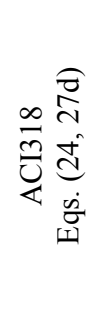 & 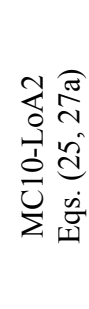 \\
\hline HS13-0T & 1655 & 1.07 & 1.09 & 1.11 & 1.05 & 0.88 & 1.50 \\
\hline HS13-CT & 1830 & 1.06 & 1.07 & 1.08 & 1.00 & 0.93 & 1.40 \\
\hline Average & & 1.06 & 1.08 & 1.09 & 1.02 & 0.90 & 1.45 \\
\hline $\mathrm{COV}$ & & 0.01 & 0.01 & 0.01 & 0.03 & 0.04 & 0.04 \\
\hline
\end{tabular}

